دراسة ظاهرة الطلاق المبكر فى ريف محافظة أسيوط

رندا يوسف محمد سلطان

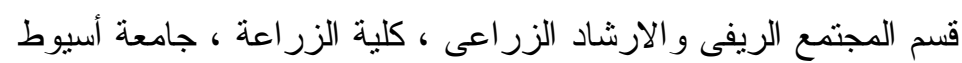

Received on: $23 / 2 / 2017$

Accepted for publication on: 11/4/2017

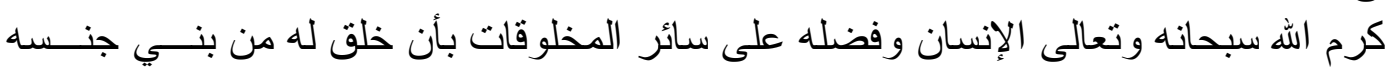

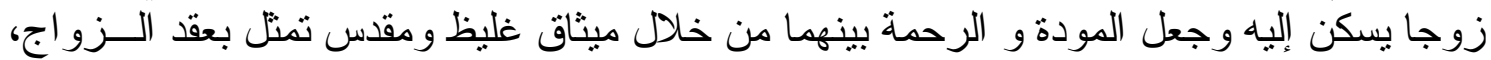

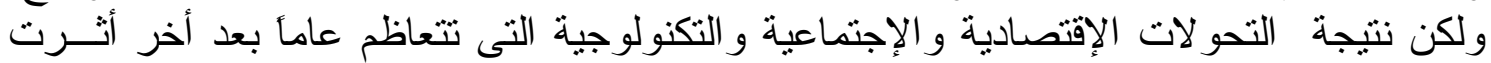

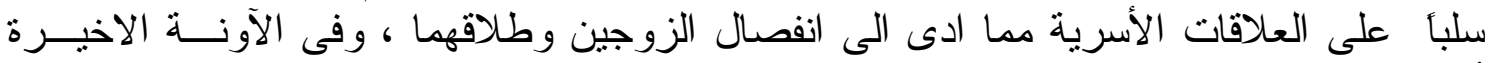

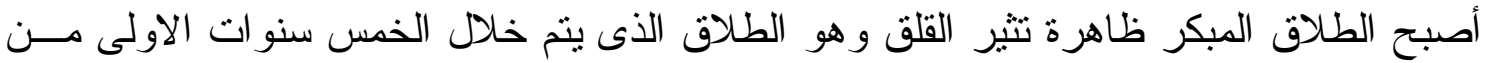

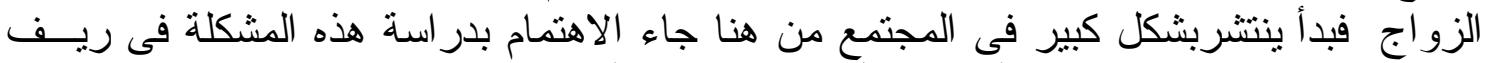

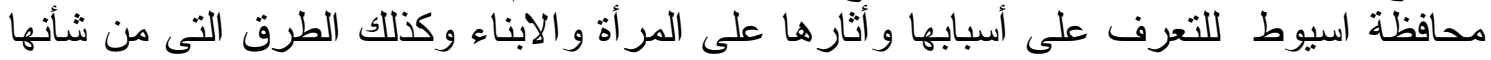

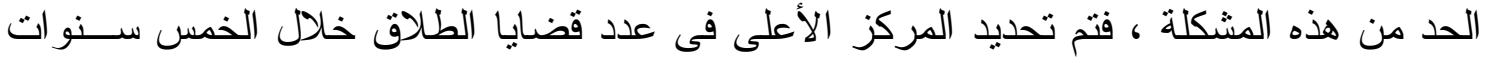

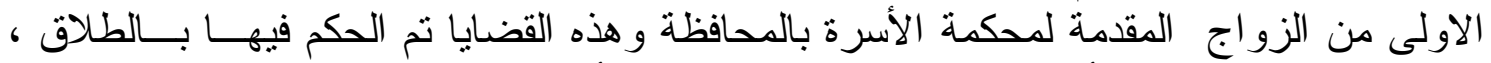

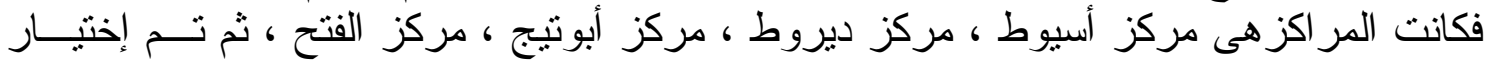

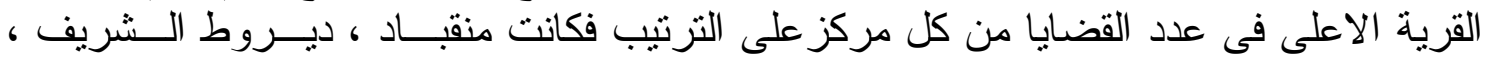

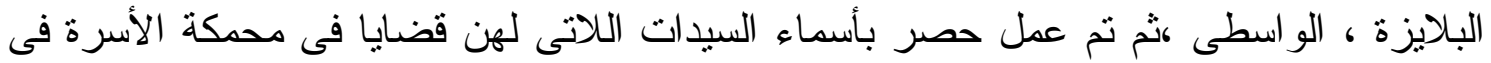

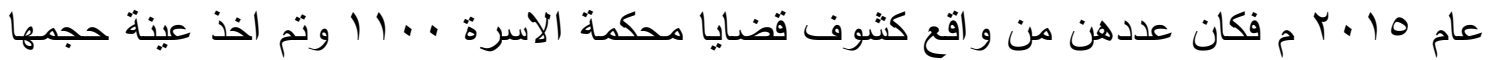

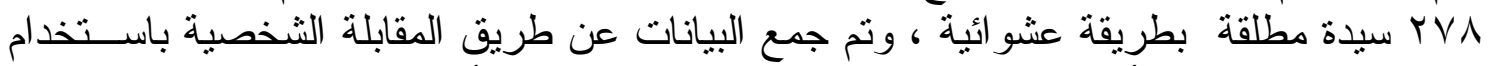

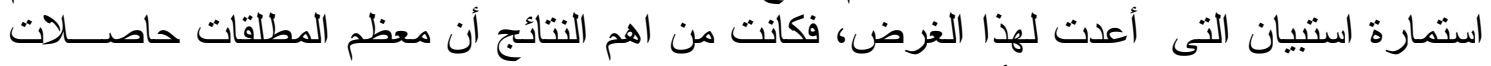

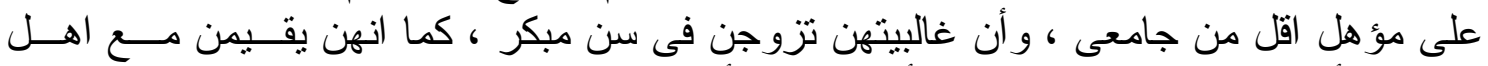

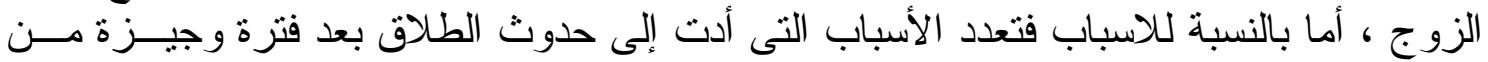

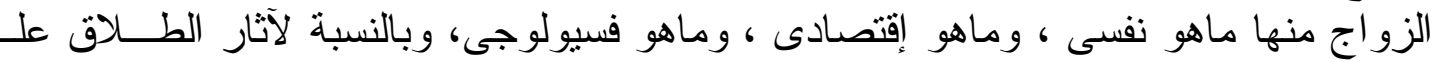

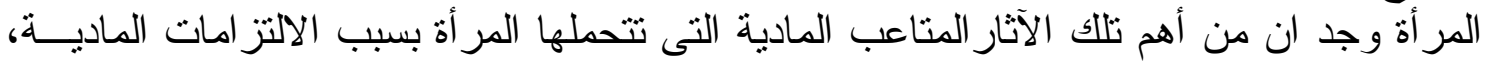

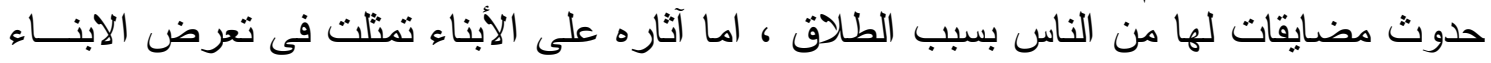

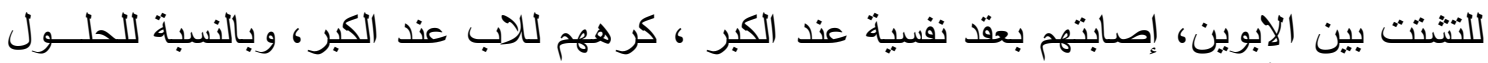

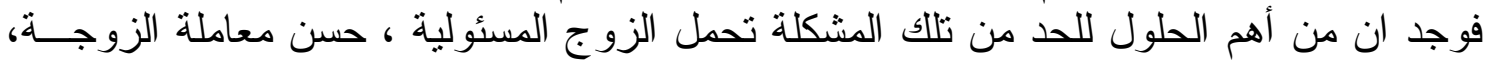
عدم تدخل الاهل ، وقدرة الزو الزول على تلبية طلبات المنزل.

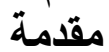

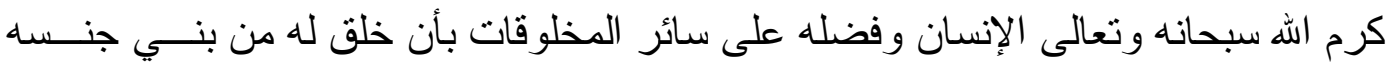

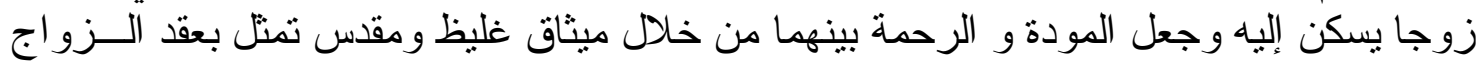

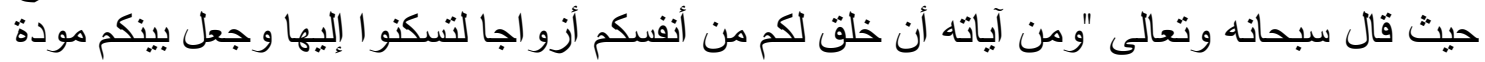

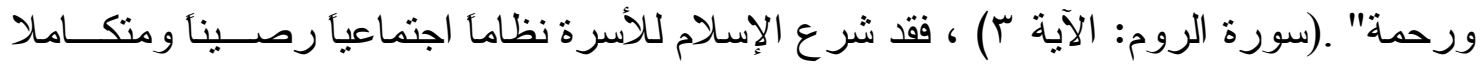

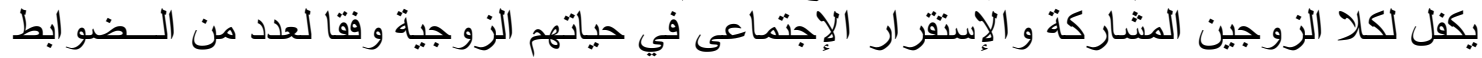

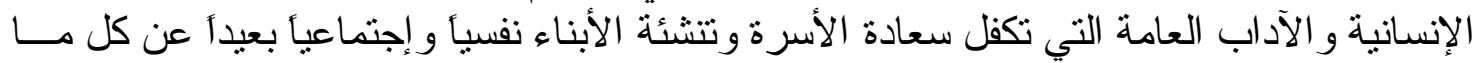

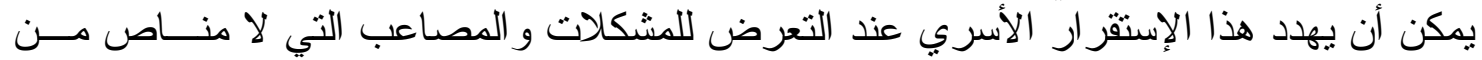

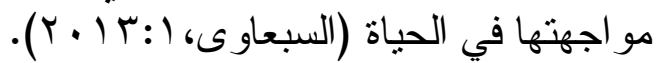

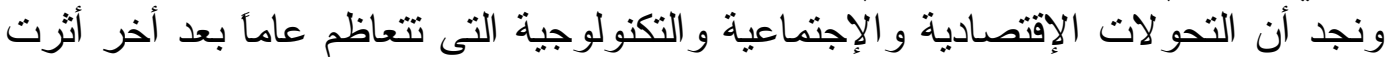

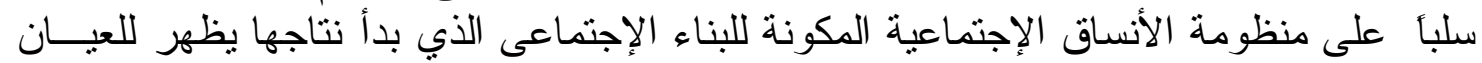

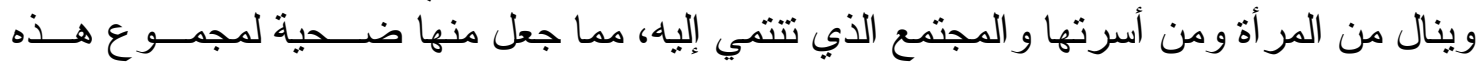


المتغير ات التي عملت على إحداث خلل في العلاقة الأسرية نتج عنه طلاقها و إنفصالها عن زوجها و وأسرتها.

فتعتبر مشكلة الطلاق من المشكلات الكبرى التى تو اجه الأسرة فبالر غم إنها مشكلة تمتهــاز

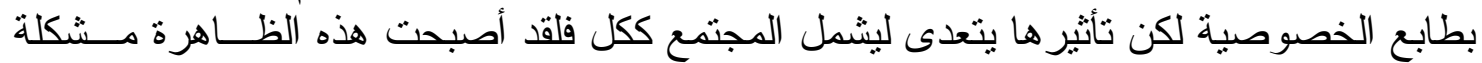

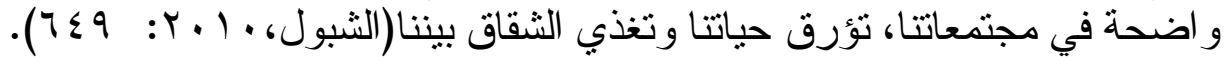

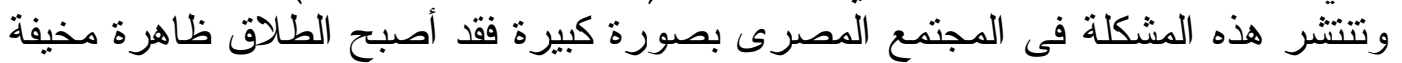

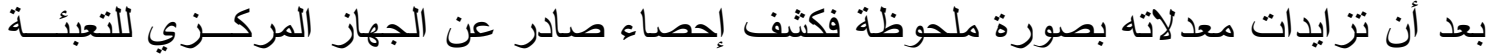

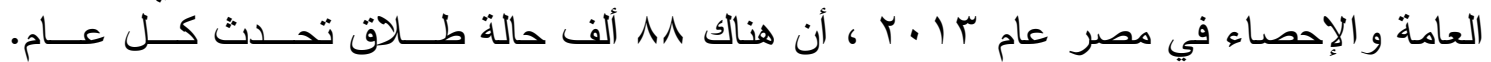

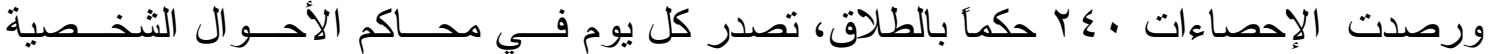

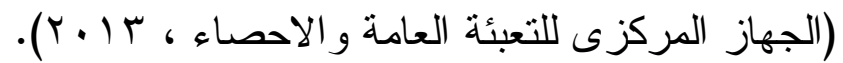

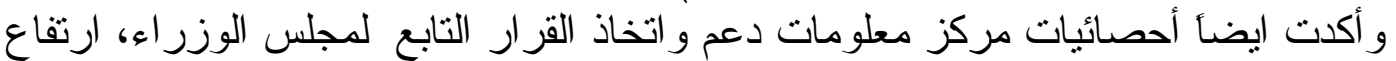

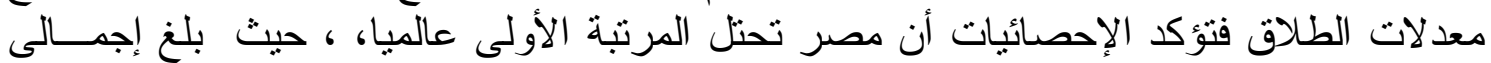

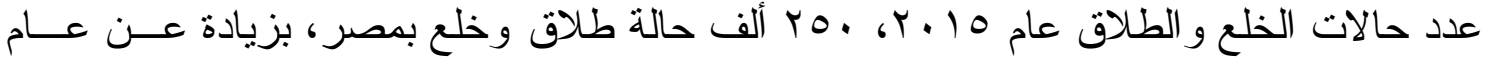

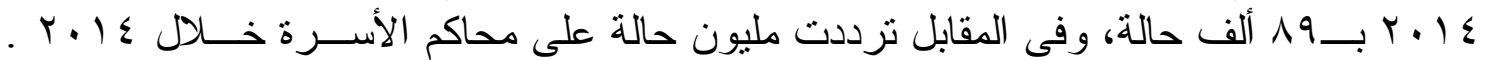

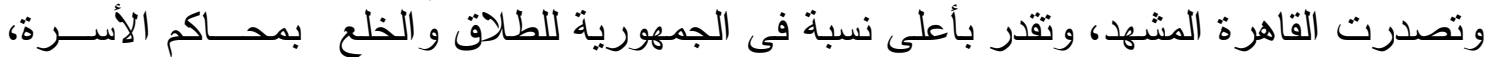

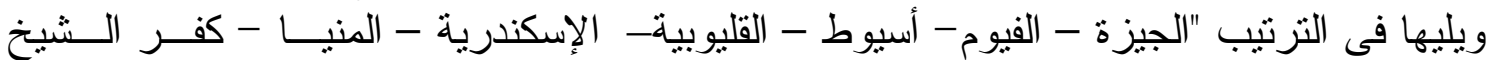

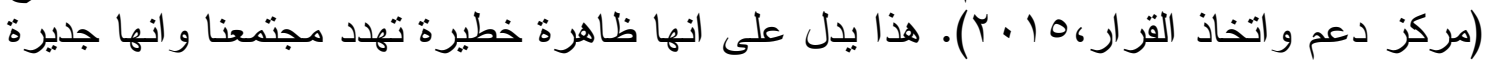

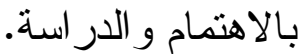
مشكلة البحث

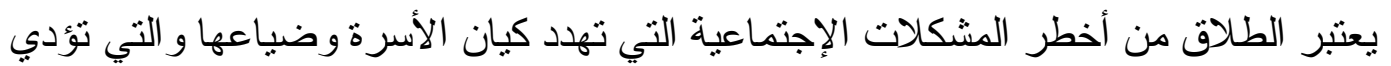

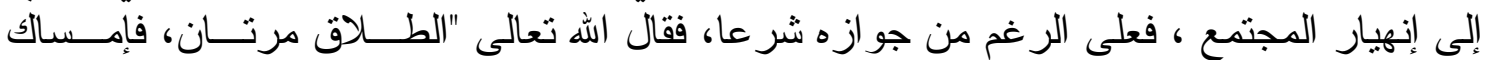

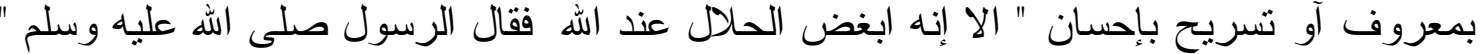

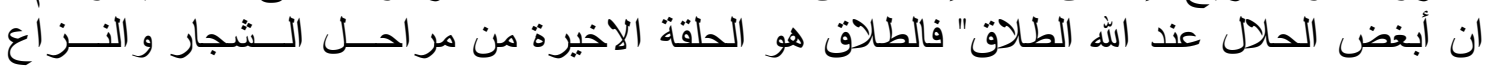

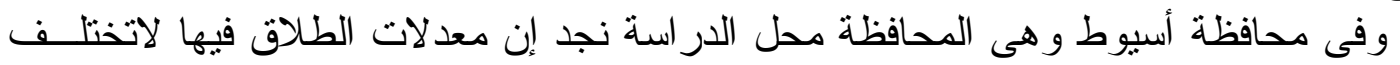

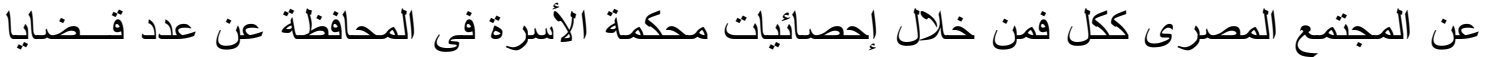
الطلاق المقدمة للمحكمة فوجد إنها تتز ايد من عام الأخر كما هو مبين بالثكل الآتى :-

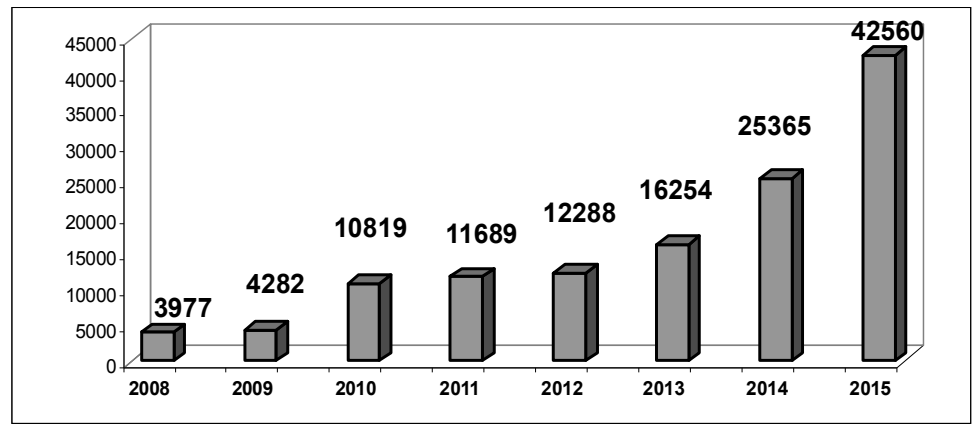

شكل رقم ( 1 ) عدد قضايا الطلاق المقدمة لدحكة الأسرة بمحافظة أسيوط من عام 1...r م الى 10 ب م م

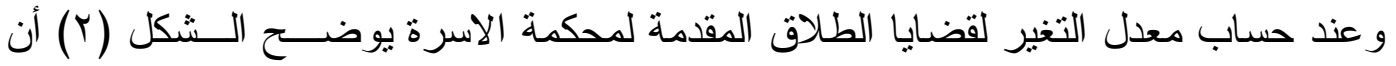
هناك تذبذب فى معدل التغير للسنو ات المختلفة. 


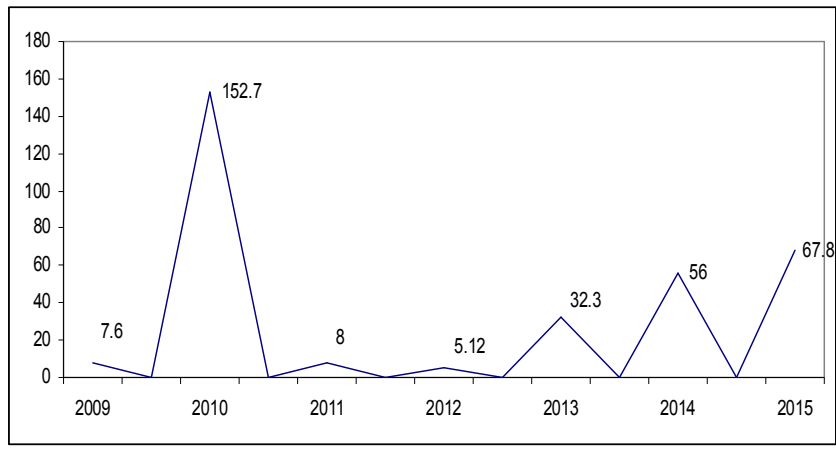

شكل (Y) يوضتح معدل التغيرفى قضايا الطلاق للسنوات المختلفة

وفى الآونة الاخيرة أصبح الطلاق المبكر ظاهرة تثير القلق وهو الطلاق الذى يتم خـــلدل

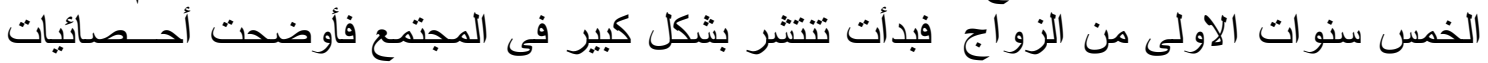

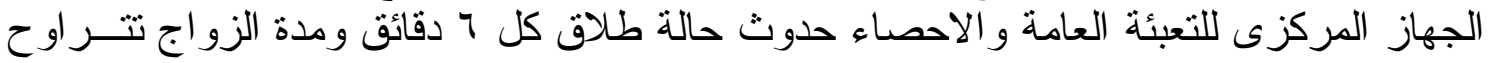

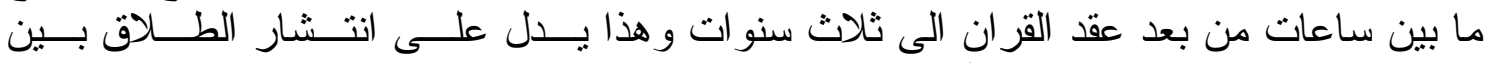

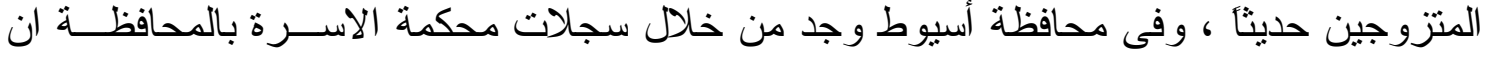

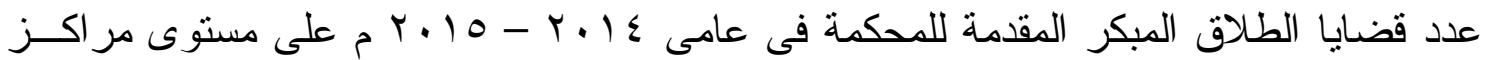

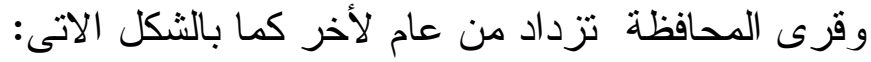

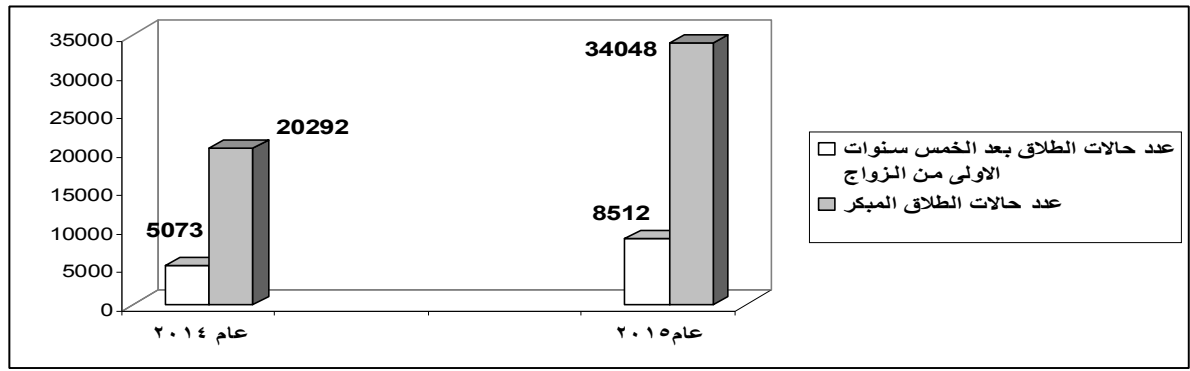

*/المصدر : سجلات محكمة الاسرة بالمحافظة

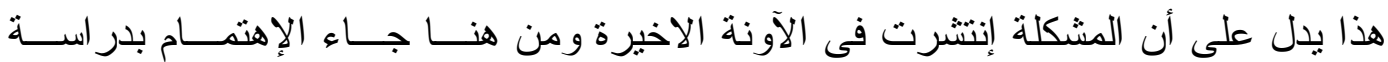

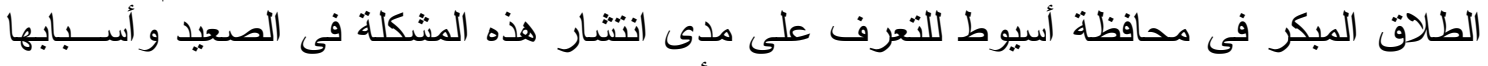
لان الاسرة هى جزء من المجتمع وعندما تكون الأسر منر ابطة قوية يكون المجتمع منر ابط قوي

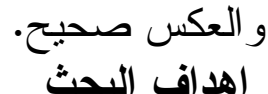

يهدف البحث الى التعرف على ظاهرة الطلاق بصفة عامة و الطلاق المبكر بصفة خاصـــة

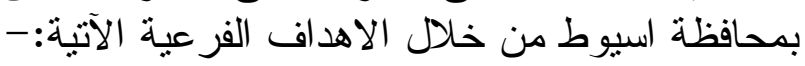
ا - التعرف على الهم الاسباب التى ادت إلى حدوث ظلهاهرة الطلاق المبكر في الآونــة الأخيــرة بريف محافظة اسيوط

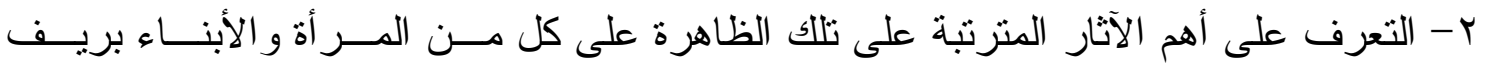
محافظة اسبوط ب- التعرف على أهم المقترحات لتقليل من حدوث تللك الظاهرة فى المجتمع

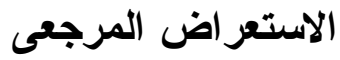

أولاً: مفهوم الطلاق من الناحية اللغوية والثر الثرعية

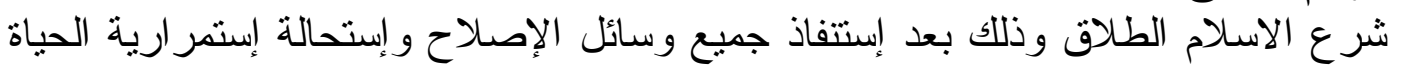

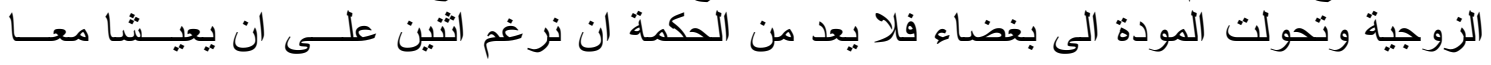




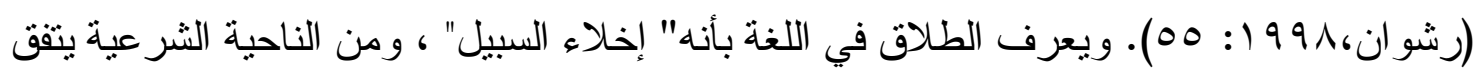

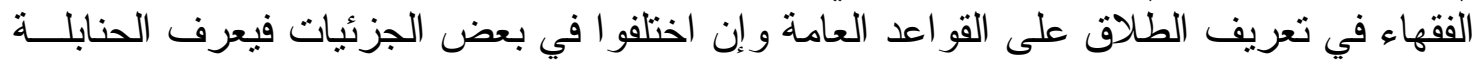

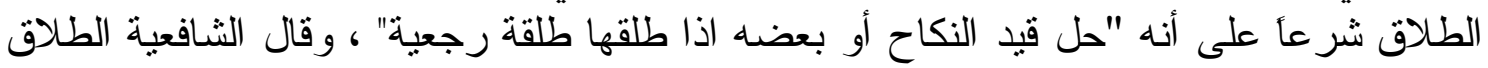

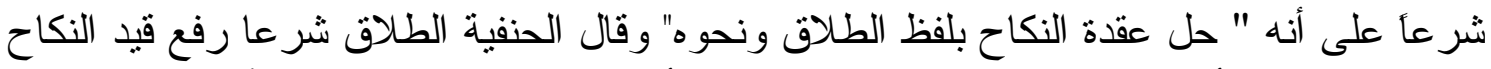

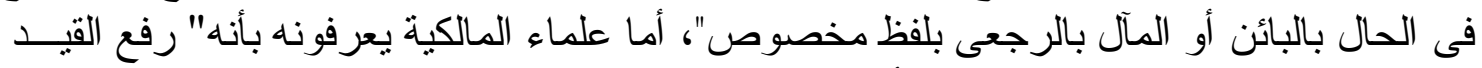

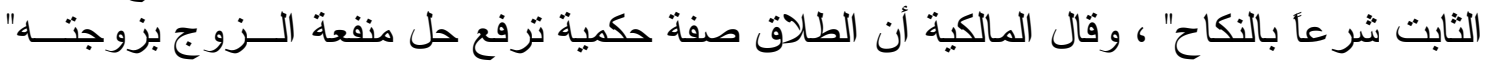

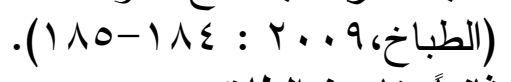

ثانياً: تاريخ الطلاق

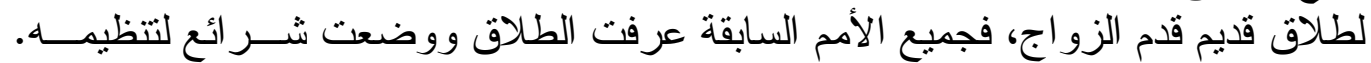

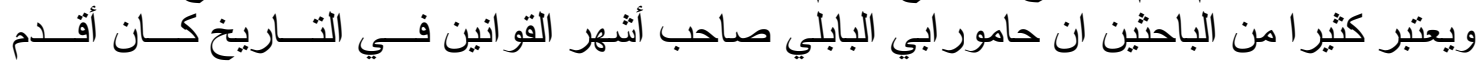

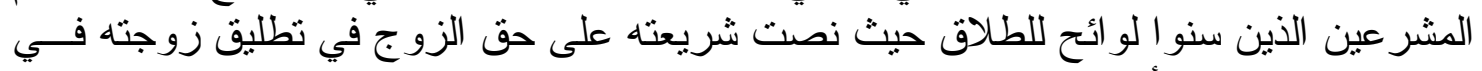

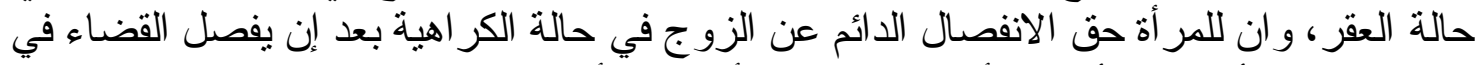

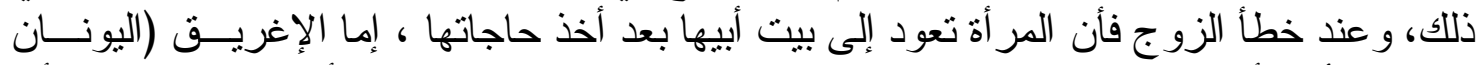

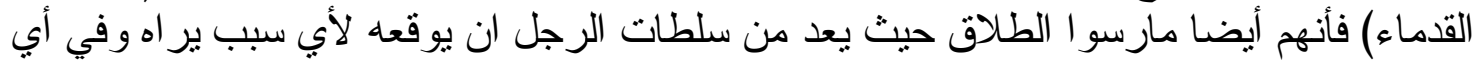

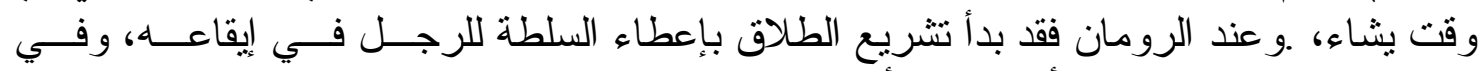

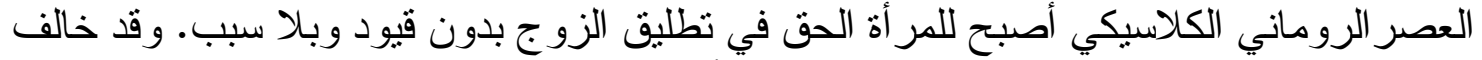

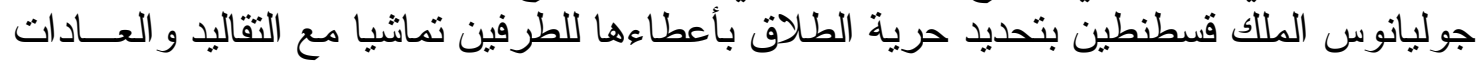

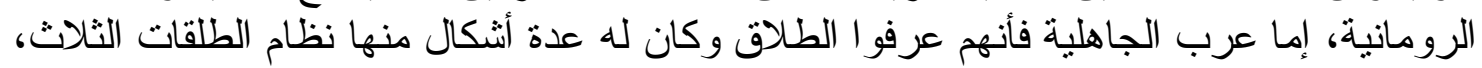

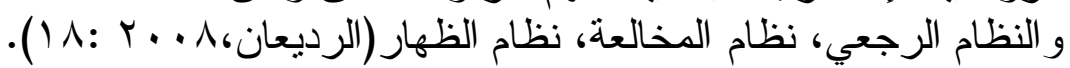

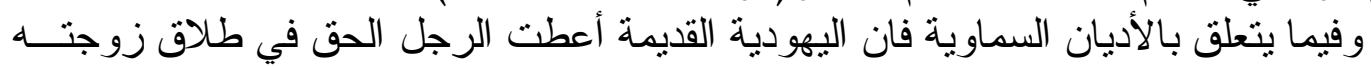

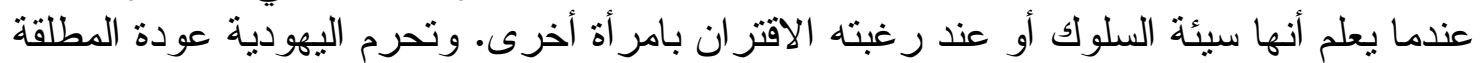

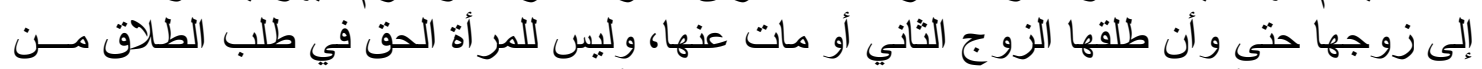

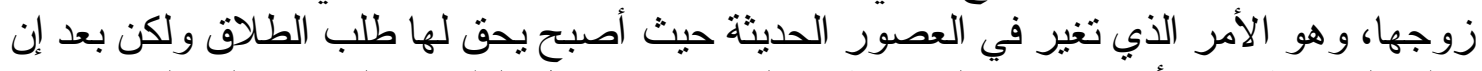

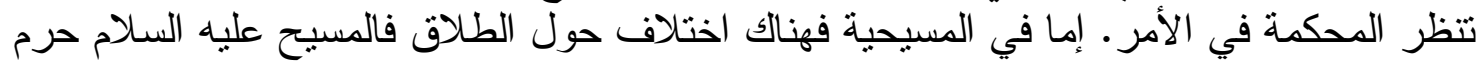

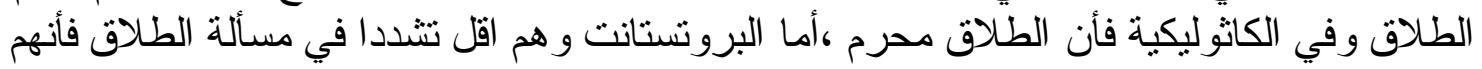

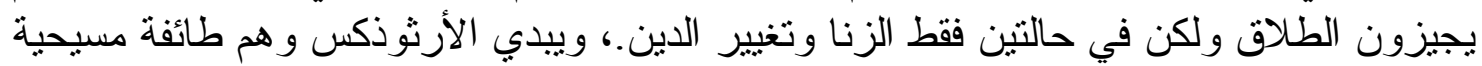

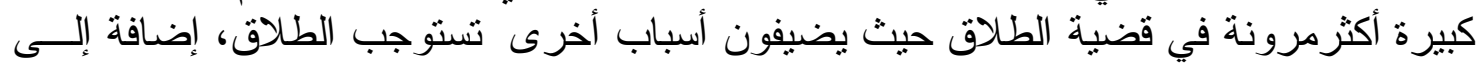

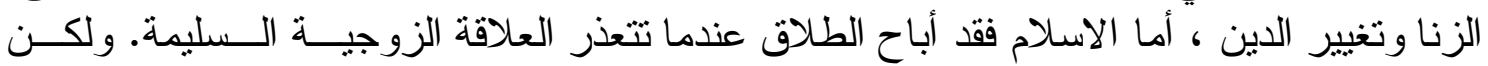

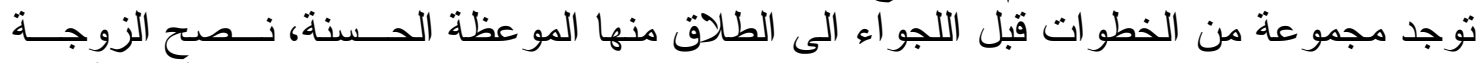

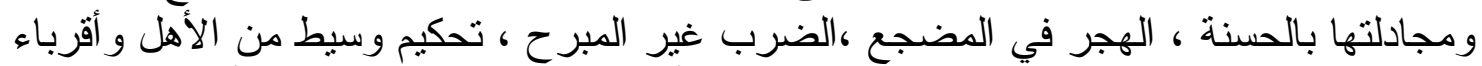

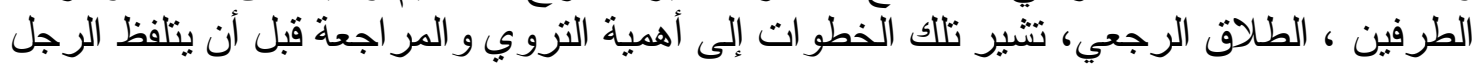

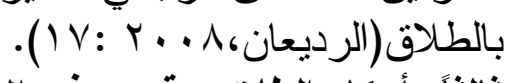

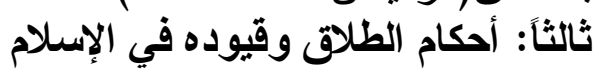

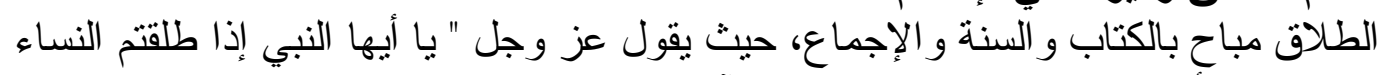

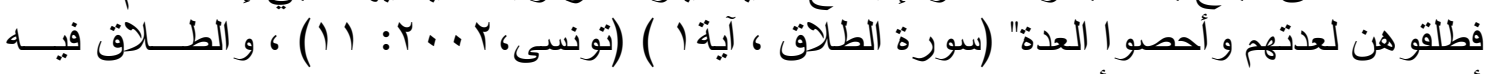

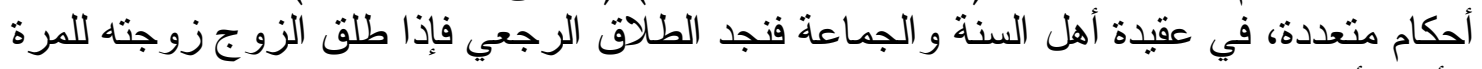

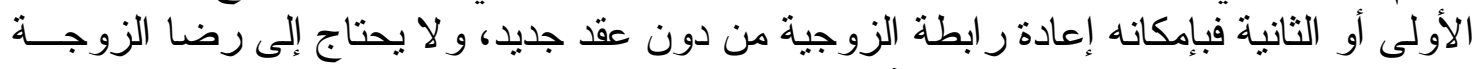

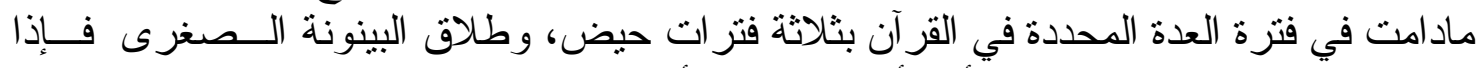

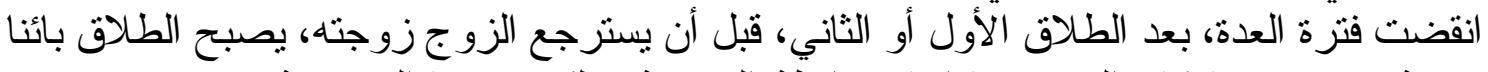

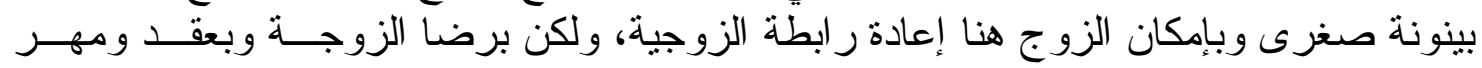

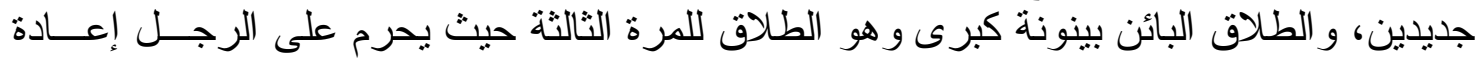


مطلقته إلا بعد أن تتكح رجل غيرهويطلقها أو يموت عنها فعندئذ يحق لها الزو اج بطليقهــا الأول

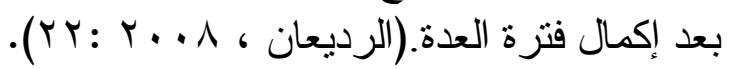

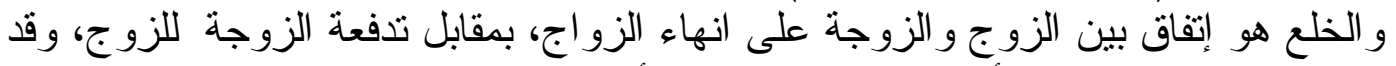

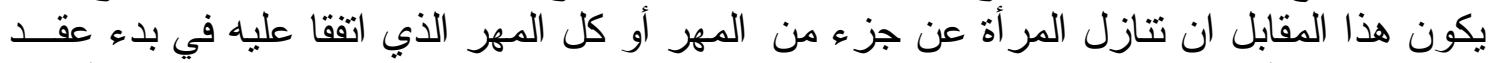

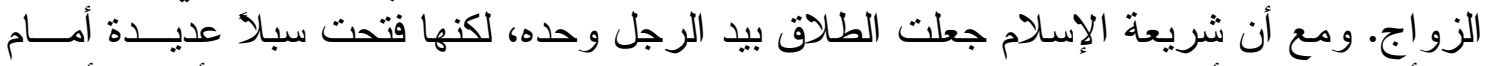

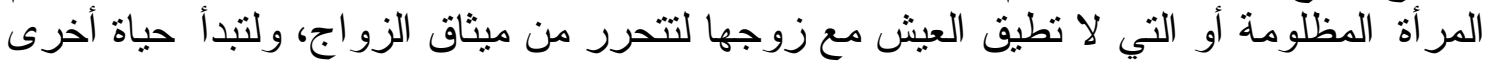

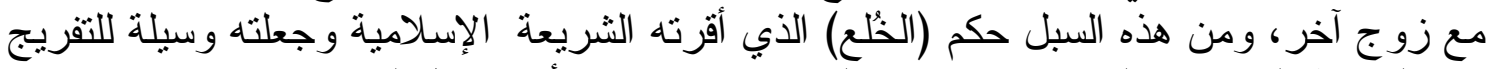

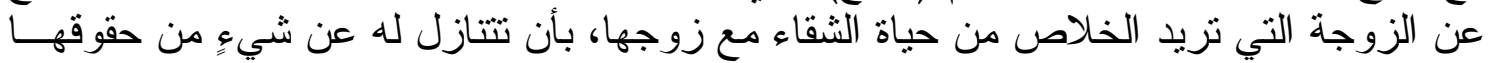

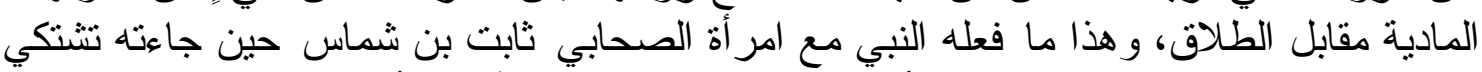

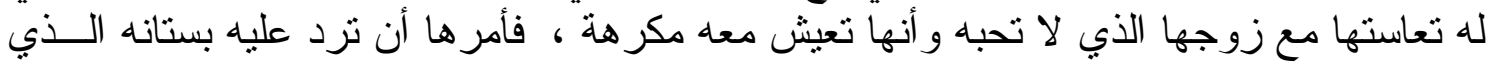

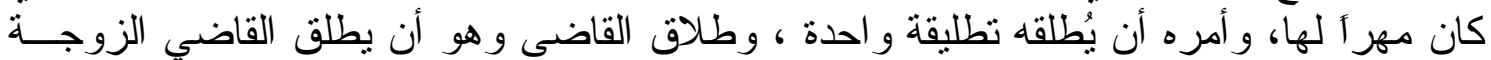

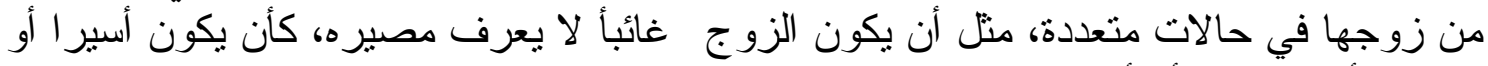

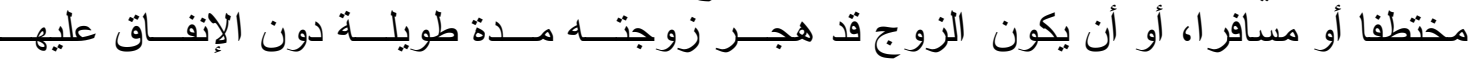

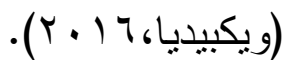

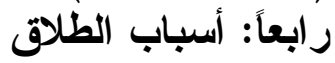

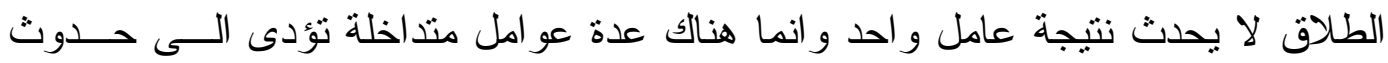

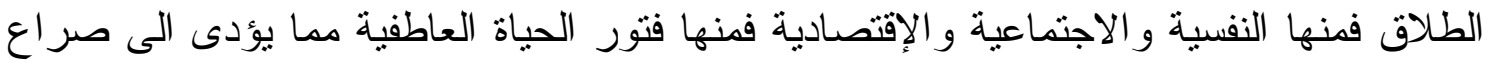

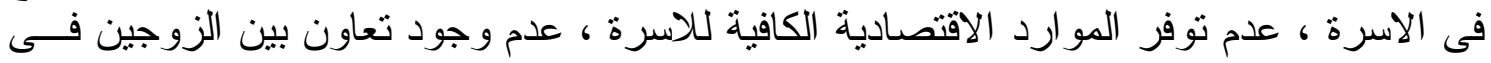

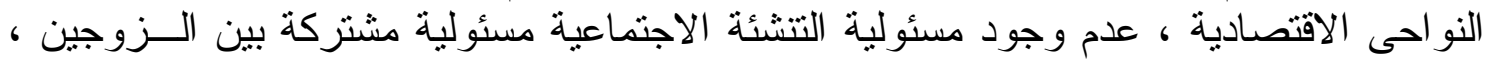

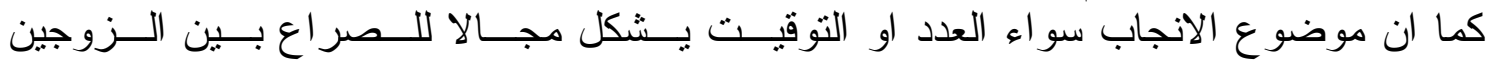

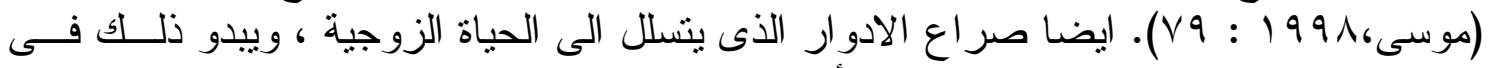

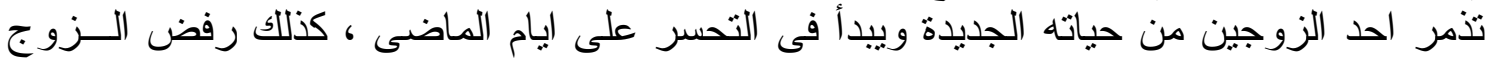

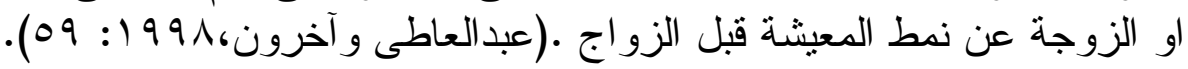

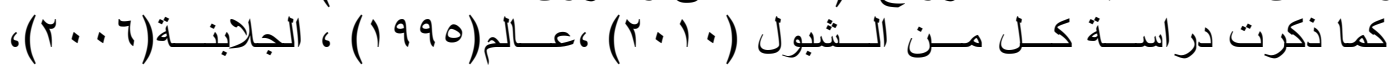

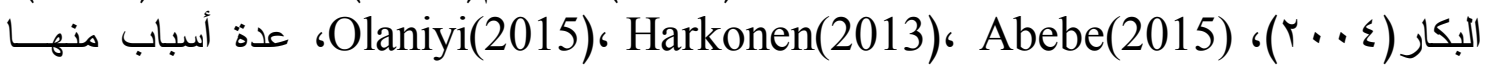

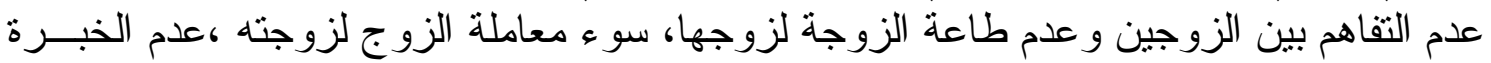

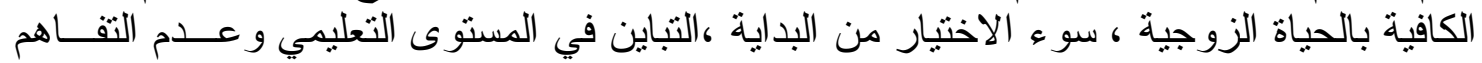

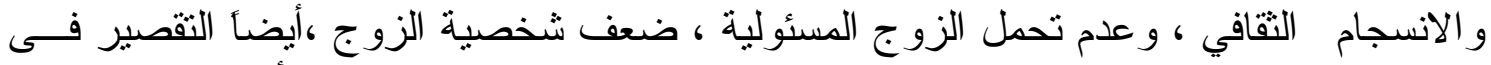

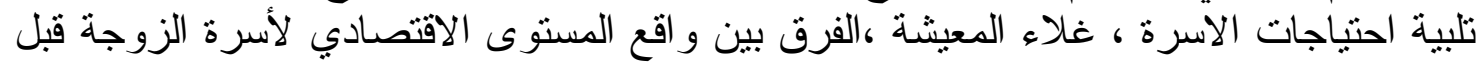

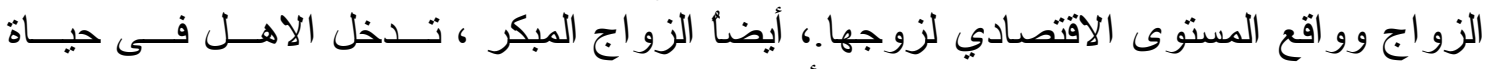

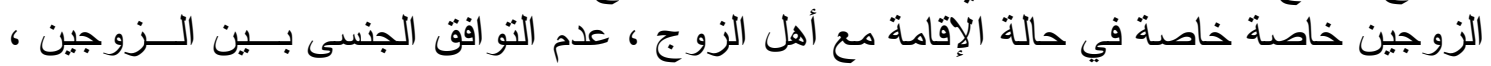

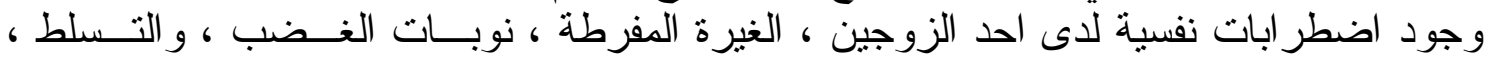

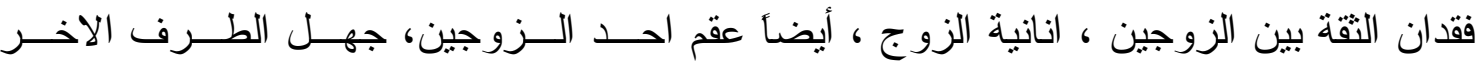

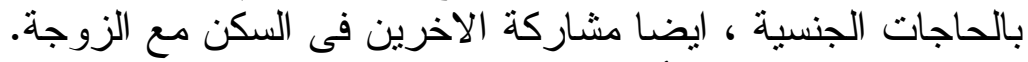

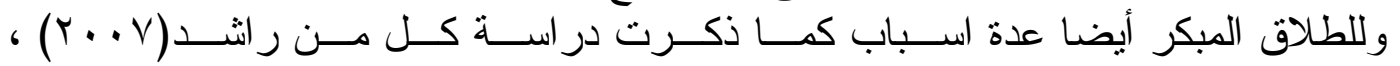

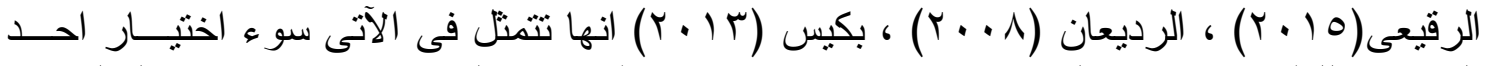

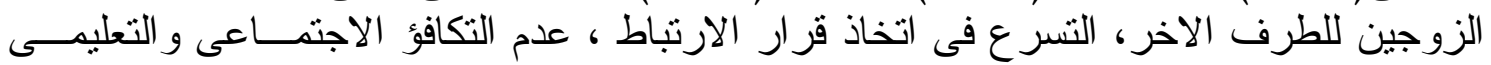

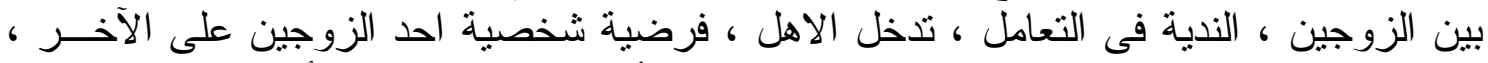

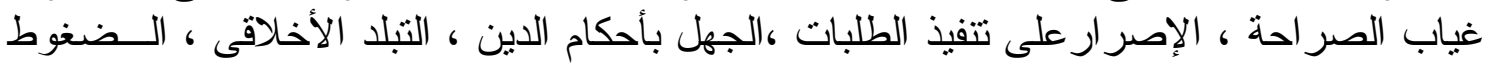

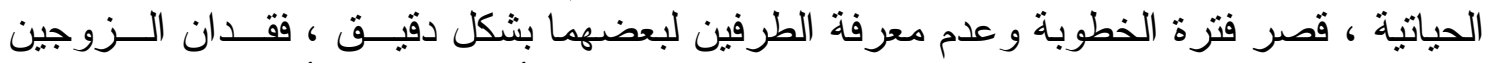

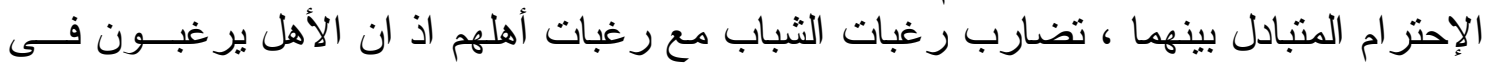




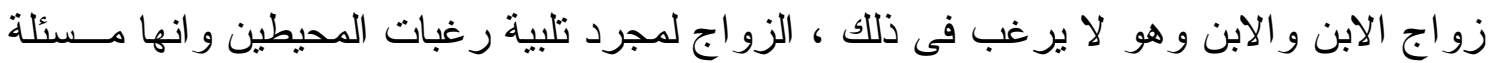

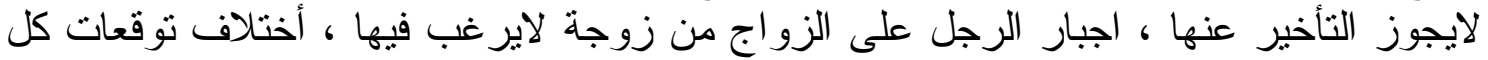

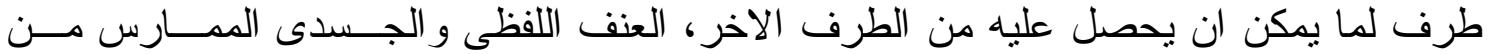

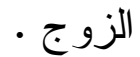

خامساً: نتائج الطلاق

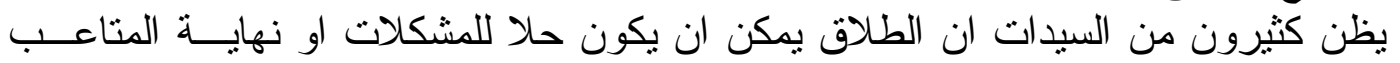

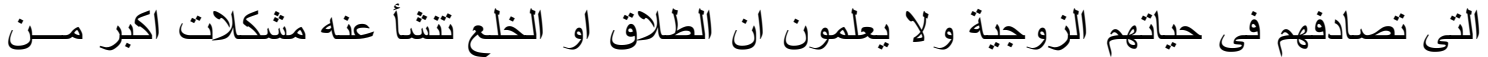

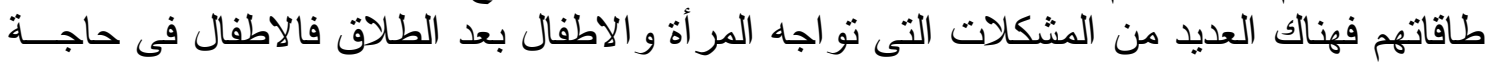

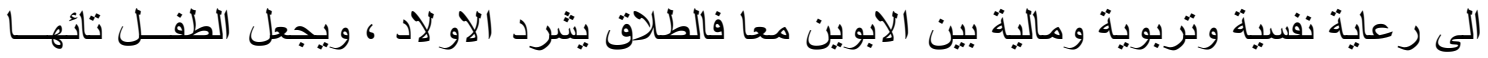

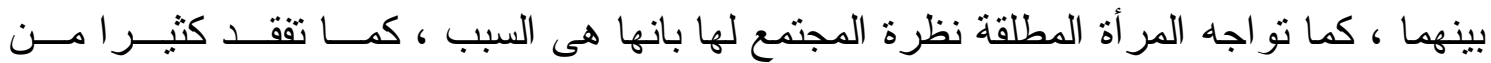

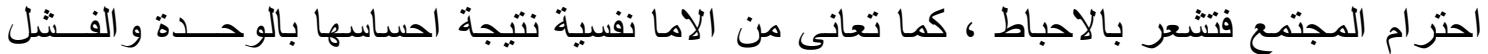

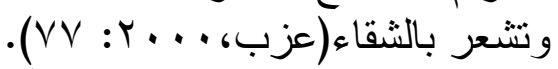

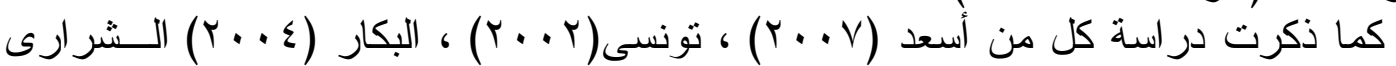

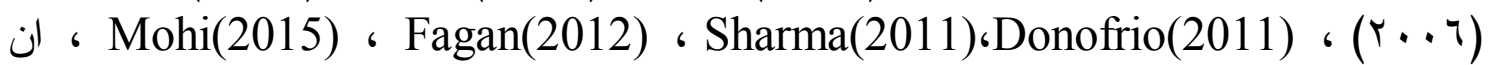

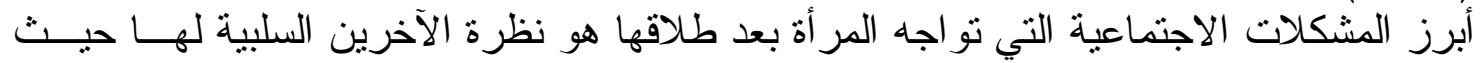

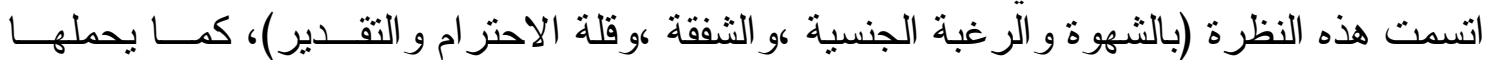

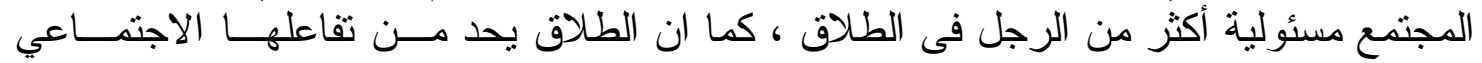

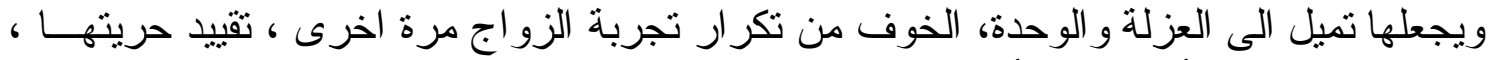

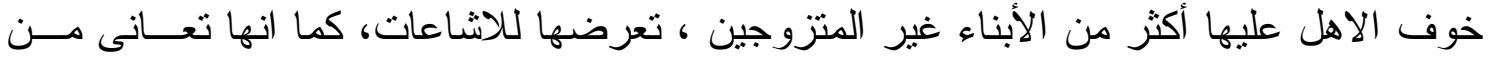

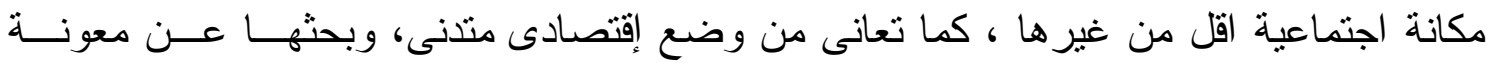

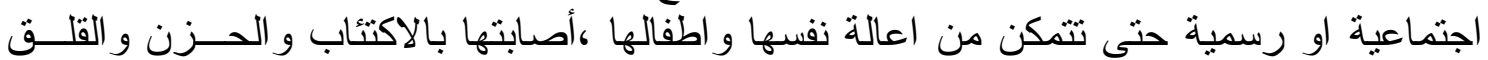

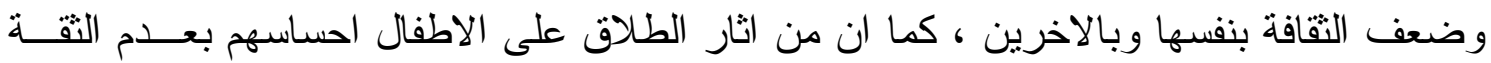

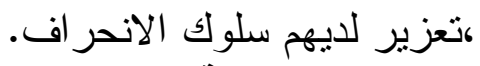

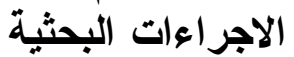
لأجر اء هذا البحث نم إنباع الخطو ات الاتية:-

1 - تحديد المجال الجغرافى البح

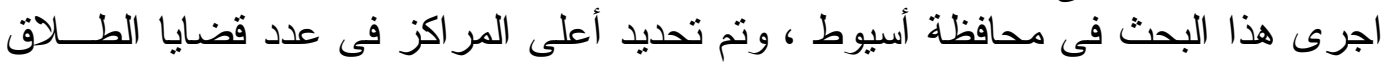

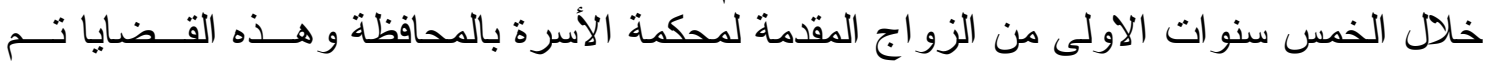

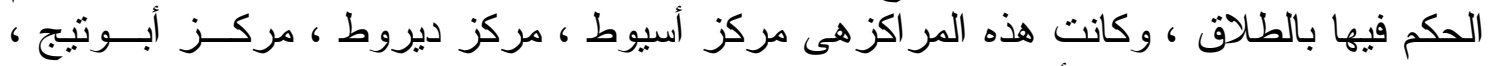

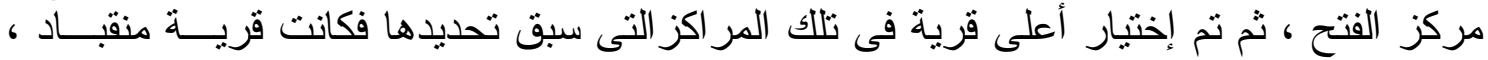
وقرية ديروط الثريف ، قرية البلايزة ، قرية الو اسطى من كل مركز على الثلى الترتيب.

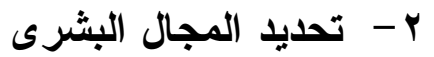

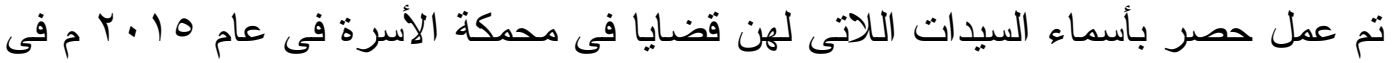

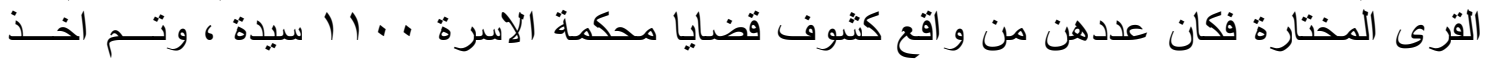

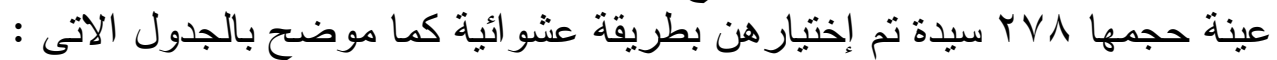

\begin{tabular}{|c|c|c|c|}
\hline العينة & الشاملة: & القرية & المركز \\
\hline$V 7$ & $\mu \ldots$ & منقباد & أسيوط \\
\hline V) & . & ديروط الشريف & ديروط \\
\hline$V r$ & 19. & البلايزة & ابوتيج \\
\hline $0 \wedge$ & rT. & الو اسطى & الفتح \\
\hline TVA & $11 \ldots$ & & الاجمالى \\
\hline
\end{tabular}




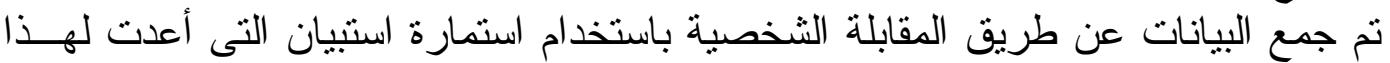

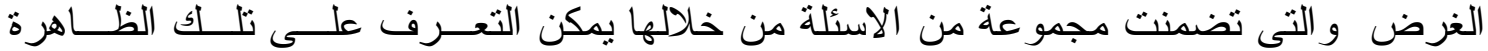

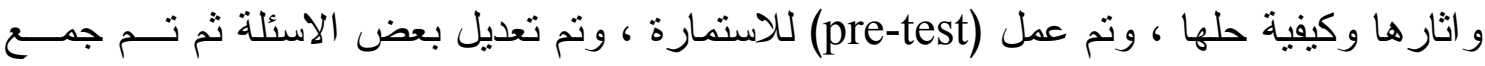
البيانات، وتم تحليل البيانات باستخدام مجمو عة البر امج الاحصائية (SPSS).

مناقثة النتائج أولاً: الخصائص الثخصية و الإجتماعية و الإقتصادية للمبحوثات الثنات

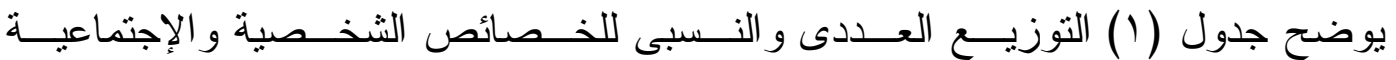

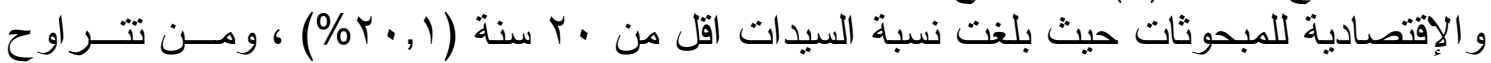

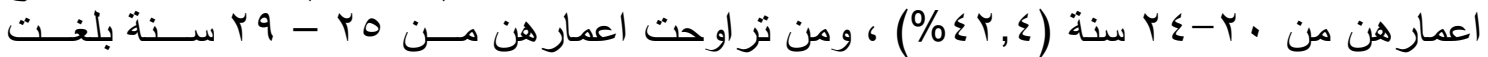

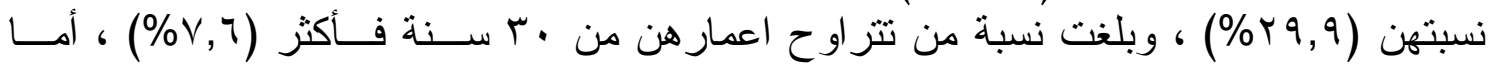

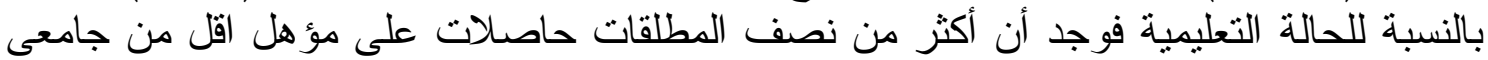

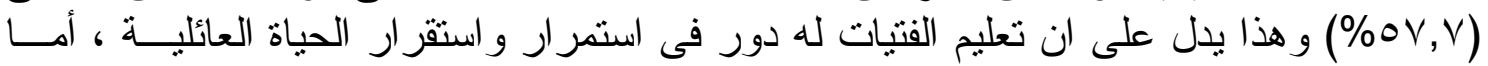

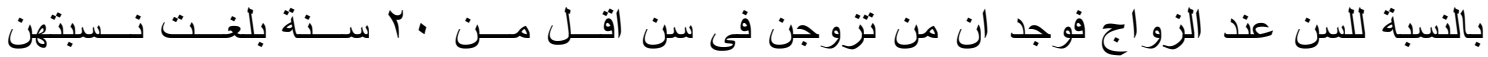

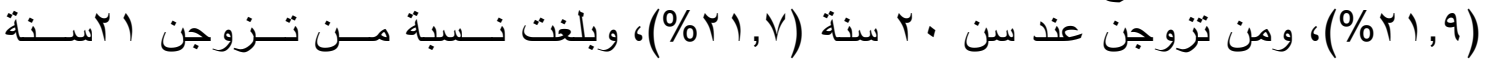

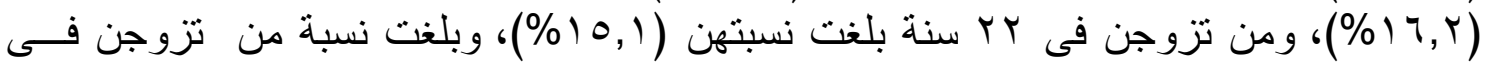

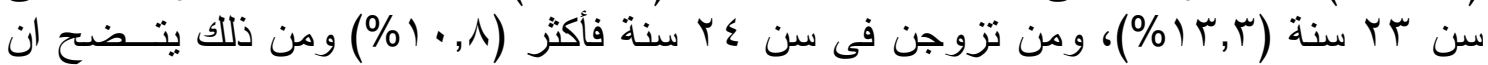

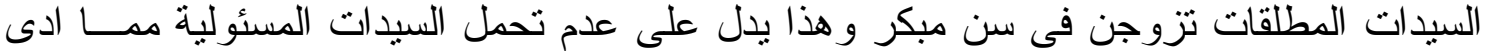
الى تدهور العلاقة الزوجية ثم الطلاق.

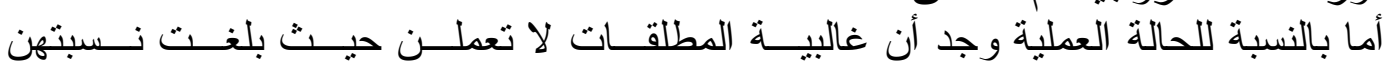

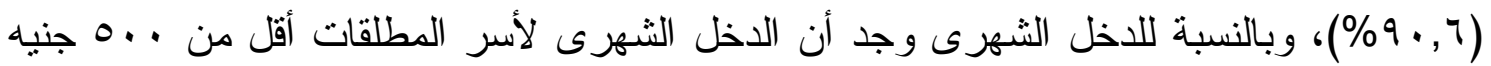

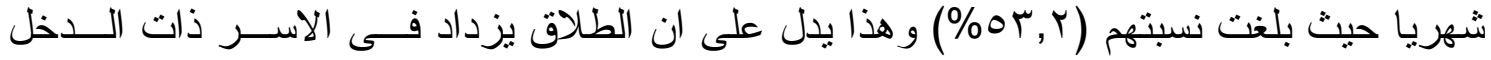

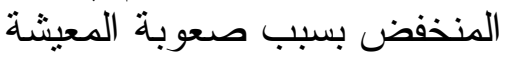

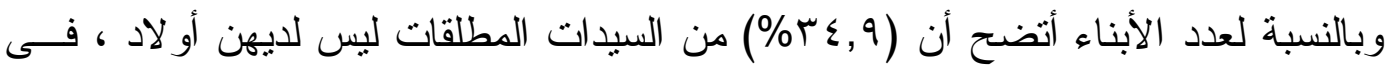

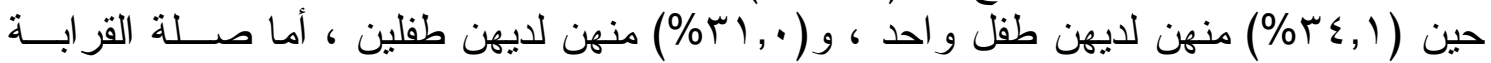

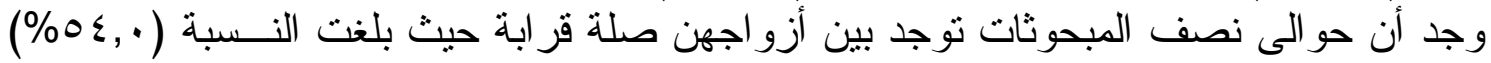

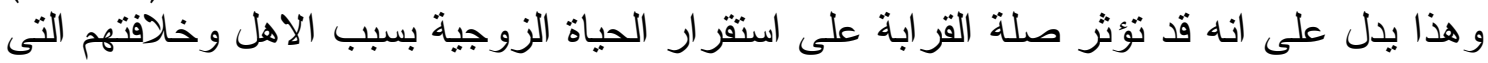

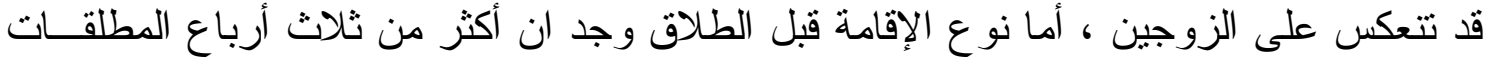

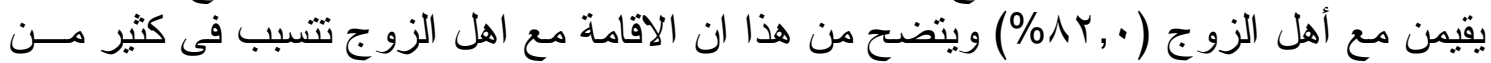

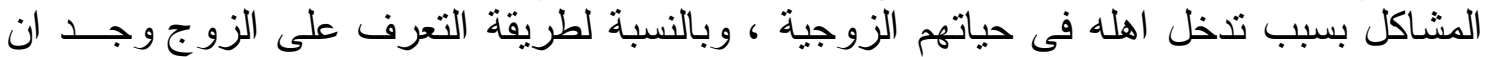

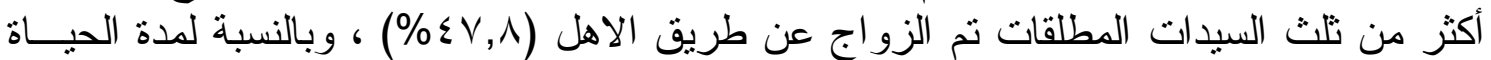

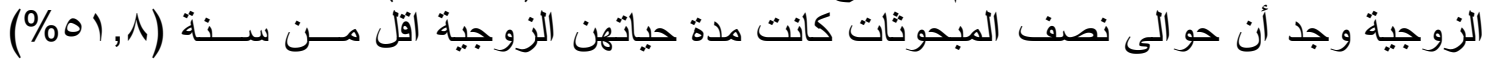

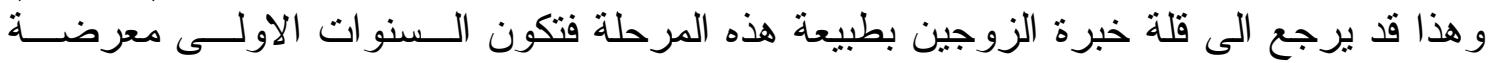

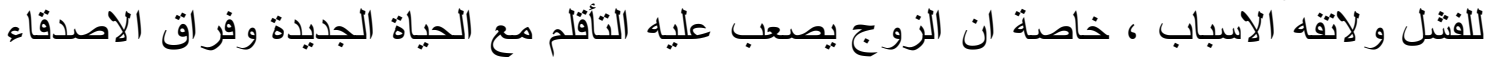

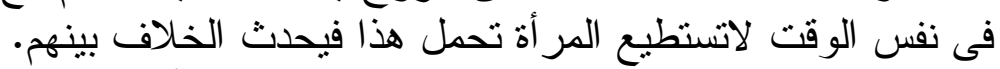

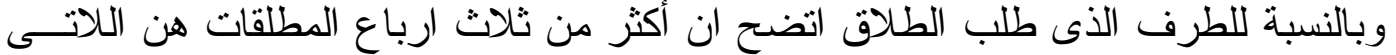

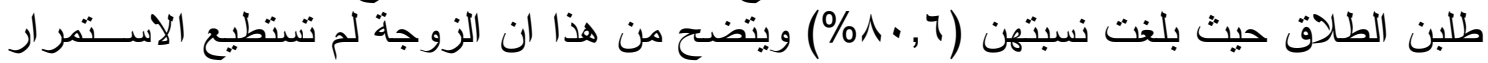

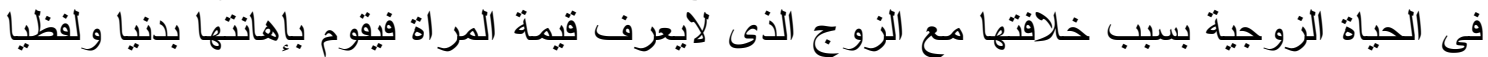

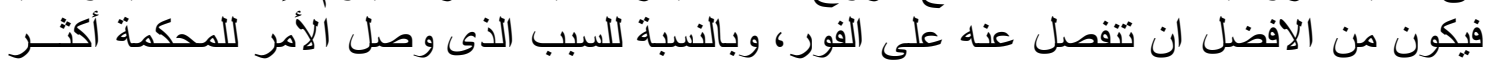

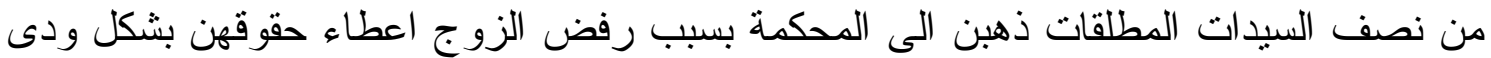

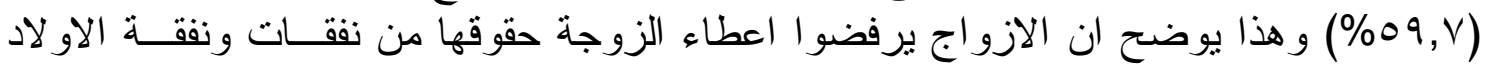




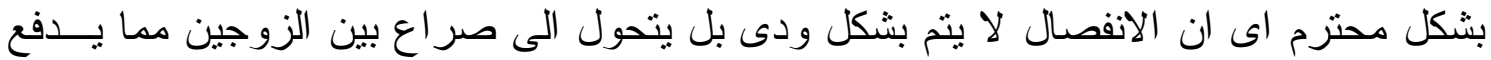

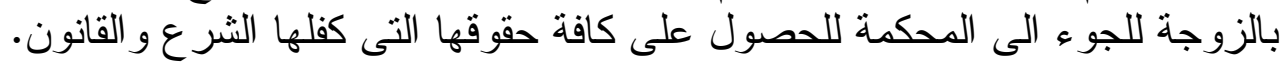

جدول ا ـ يوضح التوزيع العلدى و النسبى للخصائص الثخصية والإجتماعية والآتصادية للمبحوثات

\begin{tabular}{|c|c|c|c|c|c|c|c|}
\hline$\%$ & | العدد & تابع البيان & b & $\%$ & العدد ال العد & 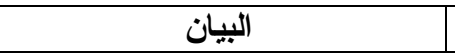 & ? \\
\hline \multirow[t]{3}{*}{$1 \cdots$} & rVA & اجمالى عدد المبحوثين & & $1 \ldots$ & TVA & اجمالى عدد المبحوثُين & \\
\hline & & & & & & أولاً: بيانات شخصية متعلقة بالزوجة & \\
\hline & & عدد الابناء & 7 & & & | - السن & 1 \\
\hline$r \varepsilon, 9$ & $9 \mathrm{~V}$ & لايوجد & & $r \cdot, 1$ & 07 & | & \\
\hline$r \xi, 1$ & 90 & طفل و احد & & $\varepsilon Y, \varepsilon$ & 111 & $r \varepsilon-r$. & \\
\hline \multirow[t]{2}{*}{$r, \cdot$} & ᄉт & طفلين & & $r q, 9$ & NT & rq-ro & \\
\hline & & صلة القر ابة & $\mathrm{v}$ & $V, 7$ & YT & $+r$. & \\
\hline $0 \leqslant, \cdot$ & 10. & توجد & & & & | الحالة التعليمية & $r$ \\
\hline \multirow[t]{2}{*}{$\varepsilon 7}$, & IrA & لا لاتوجد & & $\wedge, \Gamma$ & r & |امية & \\
\hline & & نوع الاقامةٌ قبل الطلاق & $\Lambda$ & $1 \cdot, 1$ & $r$. & أنقر أ وتكتب & \\
\hline $1 \wedge, \cdot$ & 0. & اقامة مستقلة & & $\mathrm{V}, \mathrm{T}$ & T) & | ابتدائي & \\
\hline$\Delta r, \cdot$ & rYA & اقامة مع اهل الزوج & & $V, 7$ & YI & | ل اعدادى & \\
\hline \multirow[t]{2}{*}{$\cdot$} & . & اقامة مع اهل الزوجة & & $\varepsilon r, 0$ & 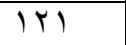 & |ثنانوى & \\
\hline & & طريقة التعرف على الزوج & 9 & YY,r & $\pi T$ & |جامعى فأكثر & \\
\hline$\varepsilon \vee, \Lambda$ & rr| & الاهل & & & & |السن غند الزواج & $r$ \\
\hline $1 \wedge, \cdot$ & 0 . & عن طريق احد افر اد الاسرة & & Y), 9 & 71 & | & \\
\hline $1 r, 9$ & rq & الجير ان & & YY,V & $7 \pi$ & $-r$. & \\
\hline \multirow[t]{2}{*}{$r, r$} & 09 & الاصقاء & & $17, r$ & $\leqslant 0$ & $-Y_{1}$ & \\
\hline & & مدة الحياة الزوجية & 1. & 10,1 & $\varepsilon r$ & $-Y Y$ & \\
\hline 01,1 & $1 \leq \varepsilon$ & اقل من سنة & & $1 \mu, r$ & te & $-Y Y$ & \\
\hline \multirow[t]{2}{*}{$\varepsilon \wedge, r$} & $1 T \varepsilon$ & 1-0-0 سنو ات & & $1 \cdot, 1$ & $r$. & $+r \varepsilon$ & \\
\hline & & الطرف الأى طلب الطلاق & 11 & & & | الحالة العملية & $\varepsilon$ \\
\hline$\Lambda \cdot, 7$ & TrE & انا & & $9, \varepsilon$ & r7 & تعمل & \\
\hline $1 V, T$ & $\sum 9$ & الطرف الاخر & & $9 \cdot, 7$ & YOY & 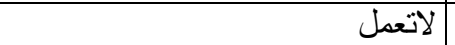 & \\
\hline \multirow[t]{2}{*}{1,1} & 0 & اهلى و اقاربى & & & & | الاخل الشهرى للأسرة & 0 \\
\hline & & السبب الذى وصل الامر للمحكمة & IT & Or, Y & $1 \leqslant 1$ & | اقل من .. & \\
\hline$\varepsilon \cdot, r$ & $11 Y$ & رفض الزوج الطلاق & & $\varepsilon 7, \wedge$ & $1 \%$ & $1 \ldots-0 \ldots$ & \\
\hline $09, \mathrm{~V}$ & 177 & رفض الزوج اعطاء حقوق الزوجة بشكل ودى & & & & & \\
\hline
\end{tabular}

المصدر : استمارة استبيان

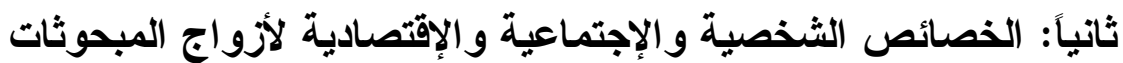

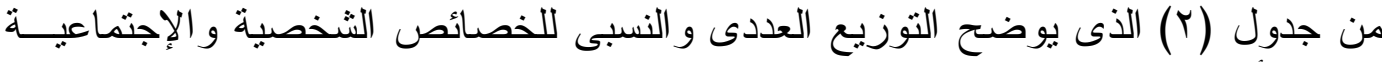

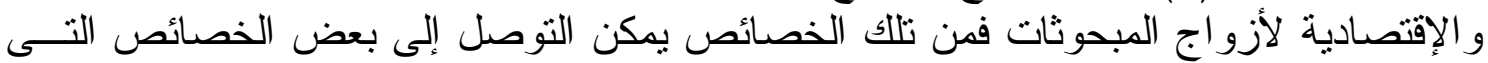

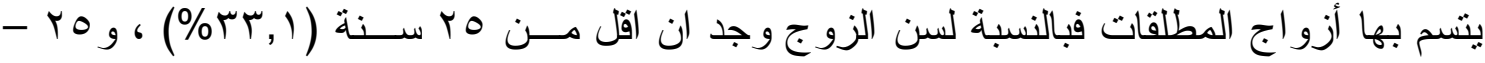

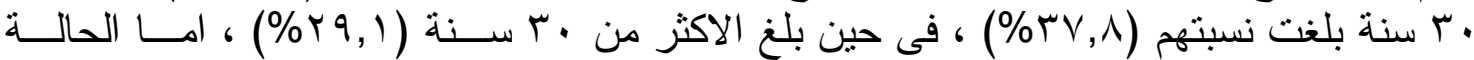

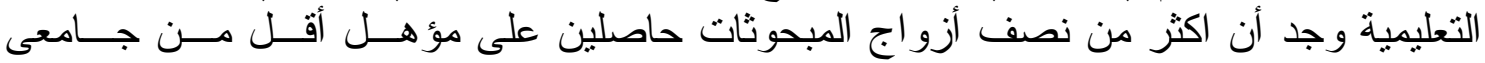

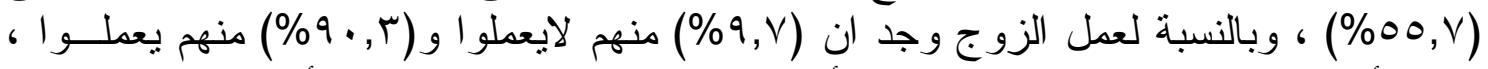

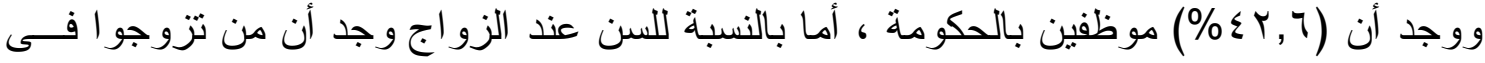

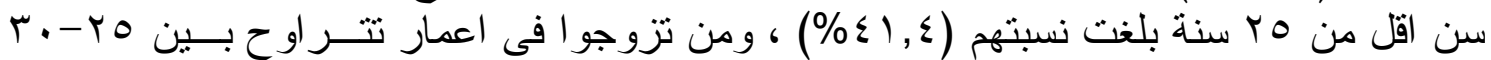

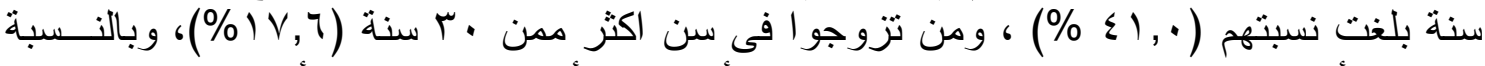

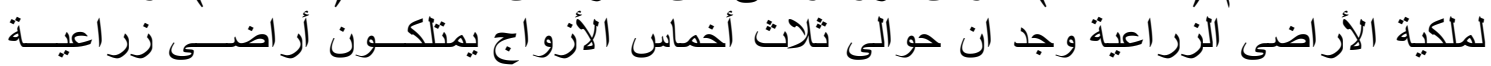
$.(\% 4), 9)$ 
جدول r · يوضـح التوزيع العددى والنسبى للخصائص الشخصية والإجتماعيــة والاقتهـصادية لأزواج

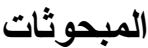

\begin{tabular}{|c|c|c|c|c|c|c|c|}
\hline$\%$ & العدد & تابع البيان & p & $\%$ & العدد & البيان البيان & i \\
\hline \multirow[t]{3}{*}{$1 \ldots$} & YVA & اجمالى عدد المبحوثين & & $1 \ldots$ & $r \vee \wedge$ & اجمالى عدد المبحوثين & \\
\hline & & & & & & ثانياً: بياتات شخصية متعلقة بالزوج & \\
\hline & & سن الزوج عند الزواج & 0 & & & سن الزوج & 1 \\
\hline$\Sigma 1, \xi$ & 110 & اقل من & & $r \mu, 1$ & 94 & اقل من Oب & \\
\hline$\Sigma 1$, & $11 \varepsilon$ & r.-Yo & & $r v, \Lambda$ & 1.0 & $r_{.-Y_{0}}$ & \\
\hline \multirow[t]{2}{*}{$1 V, 7$} & $\sum 9$ & اكثر من •r" & & $r q, 1$ & NI & أكثر من •r & \\
\hline & & ملكية الزوج لارض زراعية & 7 & & & الحالة التعليمية للزوج & $r$ \\
\hline 71,9 & IVY & 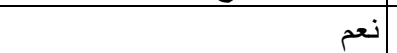 & & $9, \cdot$ & ro & |أمى & \\
\hline \multirow[t]{13}{*}{ rᄉ, I } & 1.7 & $y$ & & $1 Y, 9$ & $r 4$ & يقر اويكتب & \\
\hline & & & & $9, V$ & TV & | ابتد ائى & \\
\hline & & & & $\Lambda, 7$ & $r \varepsilon$ & | اعدادى & \\
\hline & & & & $r v, \varepsilon$ & $1 \cdot \varepsilon$ & 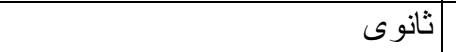 & \\
\hline & & & & TY,r & $\pi T$ & |جامعى فأكثر & \\
\hline & & & & & & عمل الزوج & $r$ \\
\hline & & & $\mathrm{V}$ & $9, V$ & TV & لايعمل & \\
\hline & & & & $9 \cdot, r$ & rol & | يعمل & \\
\hline & & & & & & مهنة الزوج (rهI) & $\varepsilon$ \\
\hline & & & & $r \wedge, r$ & $\sqrt{V 1}$ & مز مزارع & \\
\hline & & & & $1 \cdot, \cdot$ & YO & | عامل & \\
\hline & & & & 19,1 & $\varepsilon \wedge$ & اعمال حرة & \\
\hline & & & & $\varepsilon r, T$ & $1 . V$ & موظف & \\
\hline
\end{tabular}

تثانيا: اسباب الطلاق المبكر

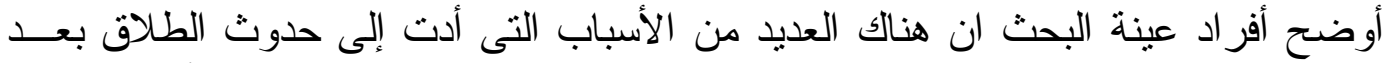

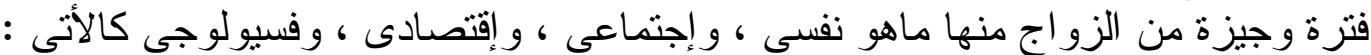

أ- أأسباب النفسية

تتمنل فى الضرب بشكل مستمر ،عدم التو افق فى العلاقة الحميمية ، سرعة الإنفعال، سوء

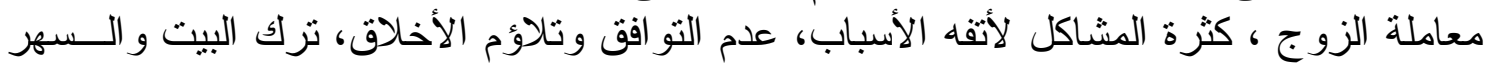

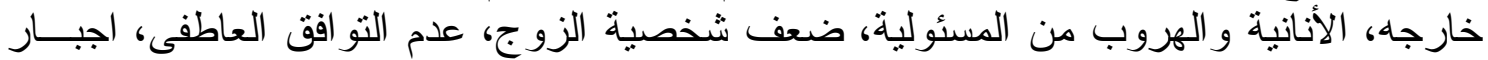

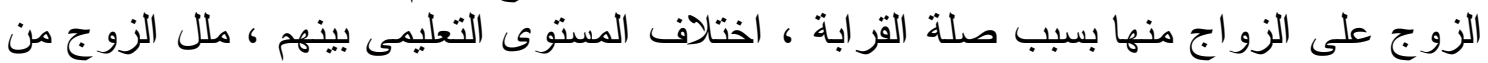
الحياة الزوجية، ضعف التقة فى الزوجة ولكن من أهم تلك الأسباب الضرب بشكل مستمر، عدم

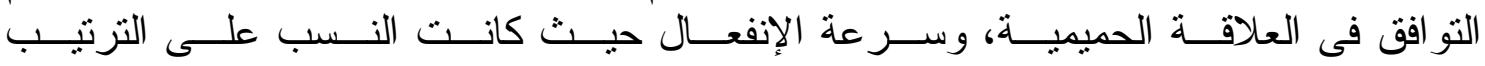

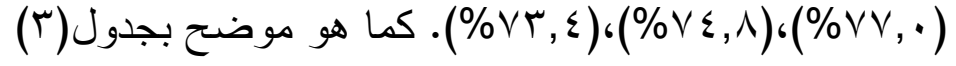


جدول r. . يوضح التوزيع العددى والنسبى للأسباب النفسية للطلاق المبكر

\begin{tabular}{|c|c|c|c|c|c|}
\hline \multicolumn{2}{|c|}{ عدم اختيار } & \multicolumn{2}{|c|}{ اختيار } & \multirow{2}{*}{ الأسباب النفسية } & \multirow[b]{2}{*}{ p } \\
\hline$\%$ & العدد & $\%$ & العدد & & \\
\hline $1 \ldots$ & $r \vee \Lambda$ & $1 \ldots$ & $r \vee \Lambda$ & اجمالى عدد المبحوثات & \\
\hline$r r, \cdot$ & $7 \varepsilon$ & $V \vee, \cdot$ & YI & | الضرب بشكل مستمر & 1 \\
\hline YO, Y & $\checkmark \cdot$ & $V \varepsilon, \wedge$ & $r \cdot \Lambda$ & |عدم التو افق فى العلاقة الحميمية & $r$ \\
\hline$r 7,7$ & $V \varepsilon$ & $\overline{V Y, \xi}$ & $r \cdot \varepsilon$ & سر عة الانفعال & r \\
\hline$\mu, r$ & $\Lambda \mathrm{V}$ & $7 \wedge, \vee$ & 191 & سوء معاملة الزوج & $\varepsilon$ \\
\hline rT,V & 91 & $T V, r$ & $1 \wedge V$ & كثرة المشاكل لأتفة الأسباب & 0 \\
\hline$\Gamma 0, \Gamma$ & 91 & $T \varepsilon, V$ & $1 \wedge$ & |عدم التو افق وتلاؤم الاخلاق & 7 \\
\hline rч,. & $1 \cdots$ & $7 \varepsilon$, & $I V A$ & |نزك البيت و السهر خارجه & $\mathrm{V}$ \\
\hline$r v, 1$ & $1 \cdot r$ & $7 r, 9$ & 180 & |الأنانية و الهروب من المسئولية & $\wedge$ \\
\hline$\varepsilon 1, \cdot$ & $11 \varepsilon$ & $09, \cdot$ & $17 \varepsilon$ & |ضعف شخصيته & 9 \\
\hline$\varepsilon \varepsilon, 7$ & IY & $00, \varepsilon$ & $10 \xi$ & | عدم التو افق العاطفى & 1. \\
\hline$\Sigma\rceil, \Sigma$ & $1 \times 9$ & Or, 7 & $1 \leq 9$ & |جباره على الزو اج منك بسبب صلة القر ابة & 11 \\
\hline 01,1 & $1 \leq \varepsilon$ & $\Sigma \Lambda, r$ & $1 T \varepsilon$ & |ختلاف المستوى التعليمى بينكم & Ir \\
\hline Or,Y & $1 \leq \Lambda$ & $\varepsilon 7, \wedge$ & $1 \pi$ & |ملل الزوج من الحياة الزوجية & $1 \pi$ \\
\hline$V I, Y$ & 191 & $r \wedge, \Lambda$ & $\Lambda$. & ضعف الثقة فيكى & $1 \varepsilon$ \\
\hline
\end{tabular}

المصدر: استمارة الاستبيان

\section{ب - الاسباب الإقتصادية}

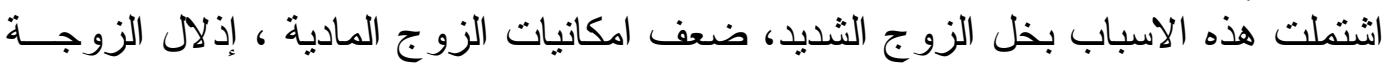

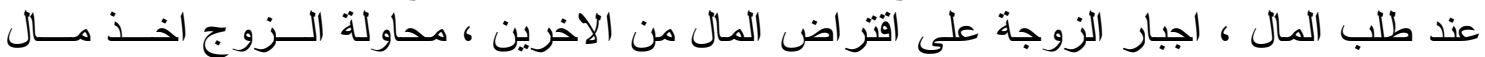

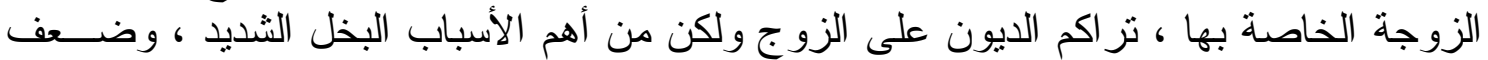

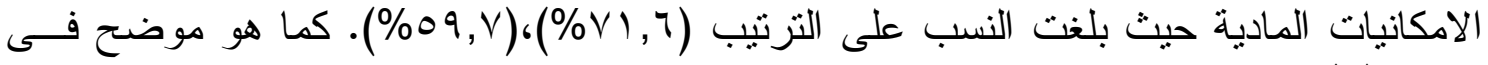

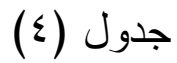

جدول ع . يوضح التوزيع العددى والنسبى للأسباب الإقتصادية للطلاق المبكر

\begin{tabular}{|c|c|c|c|c|c|}
\hline \multicolumn{2}{|c|}{ عدم اختيار } & \multicolumn{2}{|c|}{ اختيار } & \multirow{2}{*}{\multicolumn{2}{|c|}{ الأسباب الإقتصادية }} \\
\hline$\%$ & 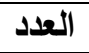 & $\%$ & 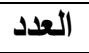 & & \\
\hline $1 \ldots$ & $r \vee \Lambda$ & $1 \cdots$ & $r V A$ & اجمالى عدد المبحوثين & r \\
\hline \^, 乏 & $\vee q$ & $v 1,7$ & 199 & البخل الثديد & 1 \\
\hline$\varepsilon \cdot, r$ & $11 r$ & $09, \mathrm{~V}$ & 177 & ضعف الامكانيات المادية للزوج & r \\
\hline$\varepsilon r, r$ & Ir. & 07,1 & 101 & إذلال الزوجة عند طلب المال & $r$ \\
\hline$\varepsilon \varepsilon, Y$ & ITr & 00,1 & 100 & اجبار الزوجة على اقتر اض المال من الاخرين & $\varepsilon$ \\
\hline$\sum \wedge, \uparrow$ & 1 ro & $01, \varepsilon$ & $1 \leqslant \mu$ & محاولة اخذ مال الزوجة الخاصة & 0 \\
\hline 07,0 & $10 \mathrm{~V}$ & $\varepsilon r, 0$ & 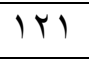 & تز اكم الديون على الزوج & 7 \\
\hline
\end{tabular}

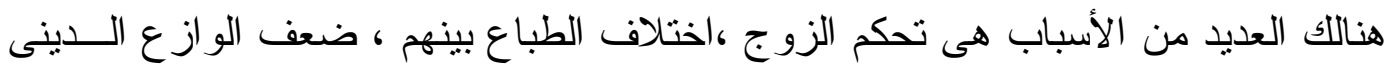

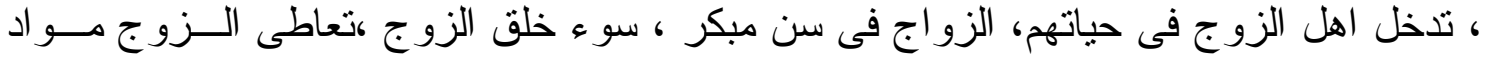

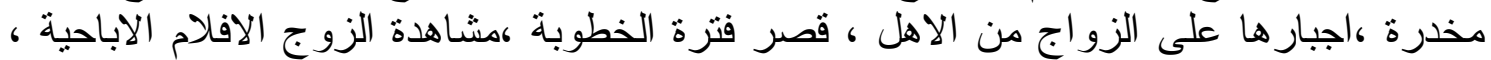

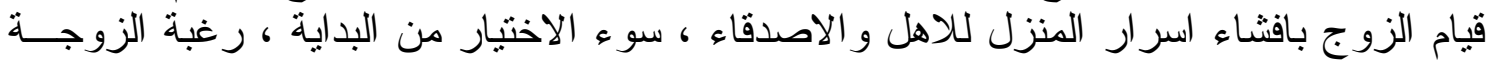

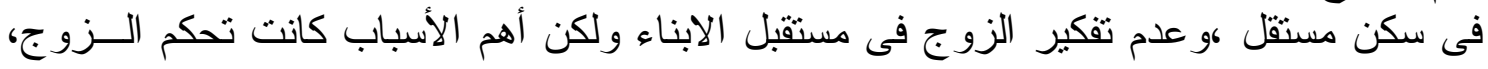




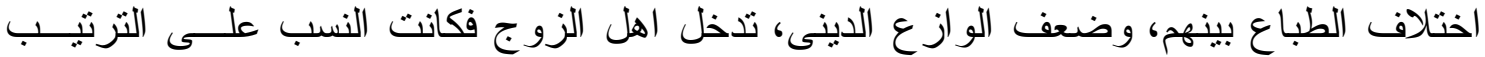

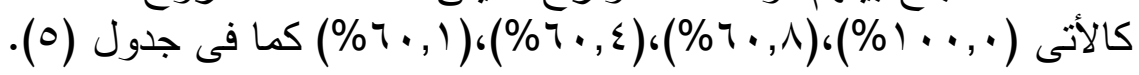

\begin{tabular}{|c|c|c|c|c|c|}
\hline \multicolumn{6}{|c|}{ جدول ه. يوضح التوزيع العددى والنسبى للأسباب الإجتماعية للطلاق المبكر } \\
\hline \multicolumn{2}{|c|}{ علدم اختيار } & \multicolumn{2}{|c|}{ اختيار } & \multirow{2}{*}{\multicolumn{2}{|c|}{ الأسباب الإقتصادية }} \\
\hline$\%$ & العدد & $\%$ & العدد & & \\
\hline $1 \ldots$ & rVA & $1 \ldots$ & YVA & اجمالى علد المبحوثين & 5 \\
\hline- & - & $1 \cdots, \cdot$ & TVA & تحكم الزوج & 1 \\
\hline$r q, r$ & 1.9 & $7 \cdot, 1$ & 179 & ا اختالف في الطباع & r \\
\hline$r 9,7$ & 11. & $7 \cdot, \varepsilon$ & 171 & ضعف الو ازع الدينى & $r$ \\
\hline$r 9,9$ & 111 & $7 \cdot, 1$ & $17 \mathrm{~V}$ & اتدخل اهل الزوج & $\varepsilon$ \\
\hline$\varepsilon r, \varepsilon$ & 111 & ov, 1 & 17. & الزو اج فى سن مبكر & 0 \\
\hline$\varepsilon r, 1$ & $11 \mathrm{~V}$ & $o v, \varepsilon$ & 171 & 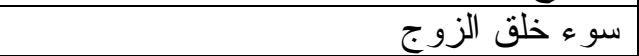 & 7 \\
\hline$\varepsilon \vee, 1$ & $1 \pi 1$ & or, 9 & $1 \leqslant V$ & ت تعاطى المو اد المخدرة & $\mathrm{v}$ \\
\hline$\varepsilon \wedge, 9$ & $1 \pi 4$ & 01,1 & $1 \leqslant r$ & الجبارك على الزواج من الاهل & $\Lambda$ \\
\hline $0 ., \varepsilon$ & $1 \leqslant$. & $\varepsilon 9,7$ & $1 \mathrm{TN}$ & قصر فنرة الخطوبة & 9 \\
\hline $0 ., \mathrm{V}$ & $1 \leqslant 1$ & $\varepsilon q, r$ & $1 T V$ & مشاهدة الافلام الاباحية & 1. \\
\hline 01,1 & $1 \leqslant Y$ & $\varepsilon \wedge, 9$ & 1,4 & اففثائه لاسر ار المنزل لاهله واصدقائه & \\
\hline 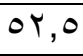 & $1 \leqslant 7$ & $\varepsilon v, 0$ & ITY & سو اء الإختيار من البداية & \\
\hline 70,1 & 111 & $r \varepsilon, q$ & $9 \mathrm{~V}$ & رغبة الزوجة فى الحصول على مسكن مستقل & \\
\hline $\mathrm{V}, \mathrm{T}$ & YIT & $r \mu, \varepsilon$ & 70 & عدم تفكيره في مستقبل الابناء & \\
\hline $1 \ldots$ & TVA & - & - & الخيانة الزوجية & \\
\hline
\end{tabular}
المصدر : استمارة الأستنيان

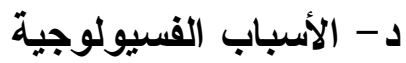

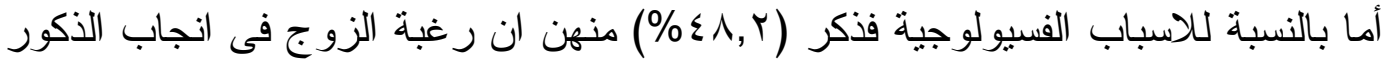

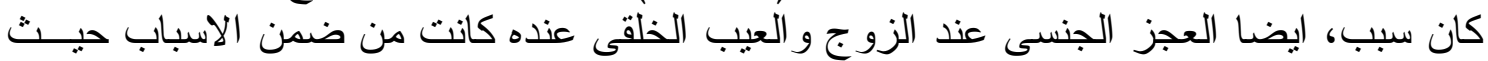

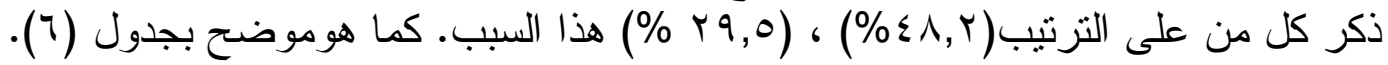
جدول 7.

\begin{tabular}{|c|c|c|c|c|}
\hline \multicolumn{2}{|c|}{ علدم اختيار } & \multicolumn{2}{|c|}{ اختيار } & \multirow{2}{*}{ الأسباب الفسيولوجية } \\
\hline$\%$ & العدد & $\%$ & العدد & \\
\hline $1 \ldots$ & TVA & $1 \ldots$ & TVA & اجمالى عدد المبحوثات \\
\hline 01,1 & $1 \leq \varepsilon$ & $\varepsilon \lambda, r$ & $1 \pi \varepsilon$ & الرغبة فى انجاب الذكور \\
\hline 01,1 & $1 \leqslant \varepsilon$ & $\varepsilon \Lambda, Y$ & $1 \pi \varepsilon$ & العجز الجنسي \\
\hline$v \cdot, 0$ & 197 & $r 9,0$ & AT & عيب خلقى عل عل \\
\hline $1 \ldots$ & TVA & - & - & مرض يستحبل معه العشرة \\
\hline
\end{tabular}

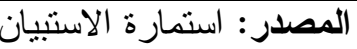

ثالثاً: اثثار الطلاق المبكر على المراة الإن الريفية

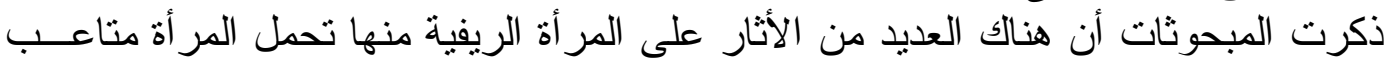

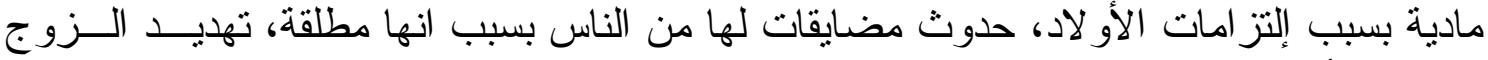

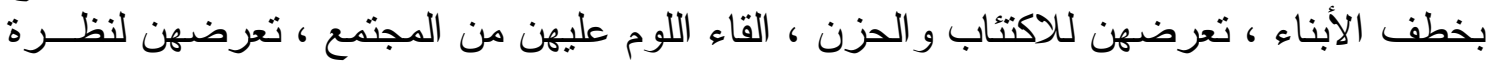

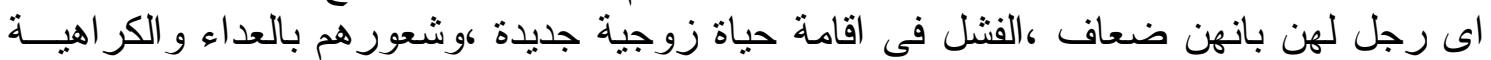

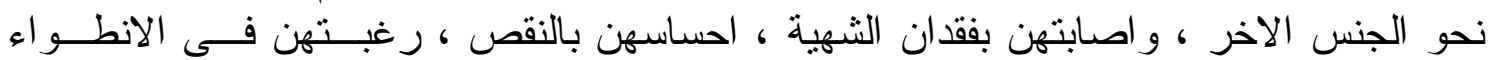

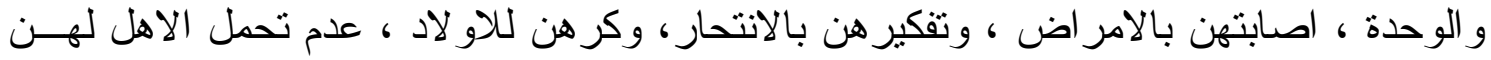




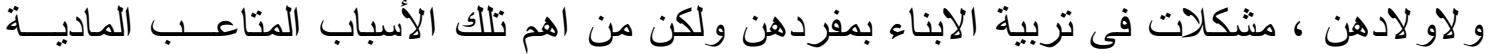

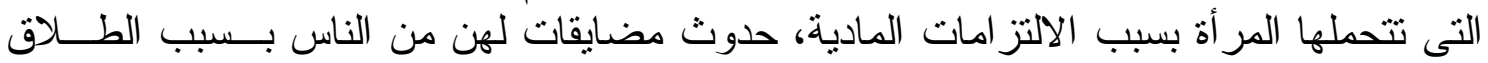

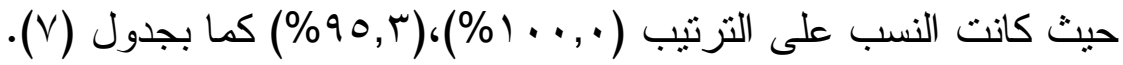

جدول V. التوزيع العددى والنسبى لأثار الطلاق المبكر على المرأة الريفية

\begin{tabular}{|c|c|c|c|c|c|}
\hline \multicolumn{2}{|c|}{ علدم اختيار } & \multicolumn{2}{|c|}{ اختيار } & \multirow{2}{*}{ أسباب الطلاق } & \multirow{3}{*}{ f } \\
\hline$\%$ & العدد & $\%$ & العدد & & \\
\hline $1 \cdots$ & TVA & $1 \ldots$ & rVA & اجمالى عدد المبحوثات & \\
\hline- & - & $1 \cdots$ & TVA & متاعب مادية بسبب التز امات الطلاق & 1 \\
\hline ir & 14 & $90, r$ & r70 & حدوث مضايقات من الناس بسبب انى مطلقة & $r$ \\
\hline$r q, 9$ & 111 & $7 \cdot, 1$ & $17 V$ & تهديد الزوج لها بخطف الابناء & $r$ \\
\hline$\varepsilon, 7$ & $11 \pi$ & $09, \varepsilon$ & 170 & الاكتئاب و الحزن & $\varepsilon$ \\
\hline$\varepsilon \varepsilon, 7$ & $1 T \leq$ & $00, \varepsilon$ & $10 \leqslant$ & القاء اللوم على من المجنمع & 0 \\
\hline$\leqslant 7$, & IYA & $0 \leqslant$, & 10. & نظرة اي رجل لى بانى ضعيفة & 7 \\
\hline$\varepsilon \wedge, 7$ & 1 To & $01, \varepsilon$ & $1 \leqslant r$ & الفشل في اقامة حياة زوجية جديدة & $\mathrm{V}$ \\
\hline$\sum 9,7$ & $1 \mathrm{\mu}$ & $0 \cdot, \varepsilon$ & $1 \leqslant$. & الشعور بالعداء و الكر اهية نحو الجنس الاخر & $\wedge$ \\
\hline $01, \varepsilon$ & $1 \leqslant r$ & $\varepsilon \wedge, \uparrow$ & $11 \% 0$ & فقدان الثهية & 9 \\
\hline Or, 9 & $1 \leqslant V$ & $\varepsilon \vee, 1$ & $1 \pi$ & احساسى بالنقص & 1. \\
\hline $0 \leqslant, \cdot$ & 10 & $\leqslant 7$, & IYA & الر غبة في الانطو اء و الوحدة & 11 \\
\hline 00, & 104 & $\leqslant 0$, & Iro & الاصـابة بالامر اض & Ir \\
\hline ov, & 109 & $\varepsilon r, \cdot$ & 119 & التفكير في الانتحار & 14 \\
\hline $0 \wedge, 7$ & $17 \pi$ & $\varepsilon 1, \varepsilon$ & 110 & كره الاو لاد & $1 \leq$ \\
\hline $7 \cdot, \Sigma$ & 171 & $r q, 7$ & 11. & عدم تحمل الاهل لى و لاو لادى & 10 \\
\hline$T \varepsilon, V$ & $1 \wedge$ & $r 0, r$ & 91 & مشكلات تربية الابناء بمفردى & 17 \\
\hline
\end{tabular}
المصدر: استمارة الاستبيان الابناء

رابعاً: اثار الطلاق المبكر على الابناء

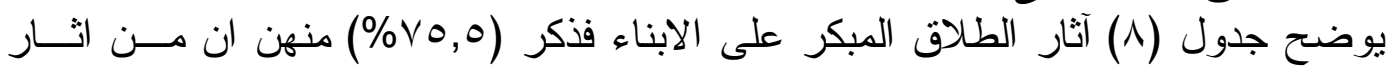

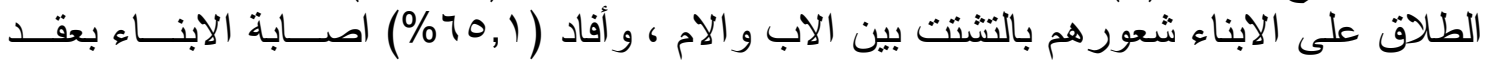

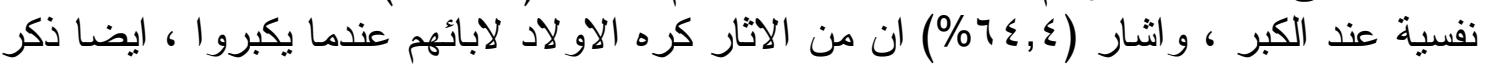
بتشت الابناء. (\%) (\%)

جدول ^. التوزيع العددى والنسبى لأثار الطلاق المبكر على الابناء

\begin{tabular}{|c|c|c|c|c|c|}
\hline \multicolumn{2}{|c|}{ علدم اختيار } & \multicolumn{2}{|c|}{ اختيار } & & \multirow{3}{*}{ e } \\
\hline$\%$ & 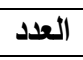 & $\%$ & العدل & اتار الطلاق على الابناء & \\
\hline $1 \ldots$ & TVA & $1 \ldots$ & rVA & اجمالى عدد المبحوثات & \\
\hline$r \leqslant, 0$ & 71 & $v 0,0$ & r. & شعور هم بالثتشت بين الاب و الام & 1 \\
\hline$r \varepsilon, 9$ & $9 V$ & 70,1 & 111 & | اصابتهم بعقد نفسية عند الكبر & $\bar{r}$ \\
\hline$r 0,1$ & 99 & $T \varepsilon, \varepsilon$ & 179 & | كر ههم لابائهم عند الكبر & $r$ \\
\hline$r, r$ & 1.1 & Tr, & IVY & | تثترد الابناء & $\varepsilon$ \\
\hline
\end{tabular}

المصدر : استمارة الاستبيان

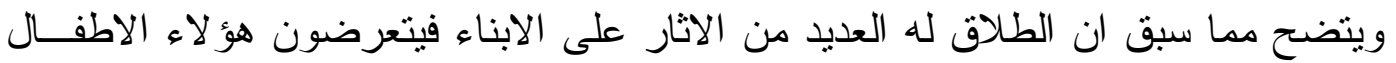

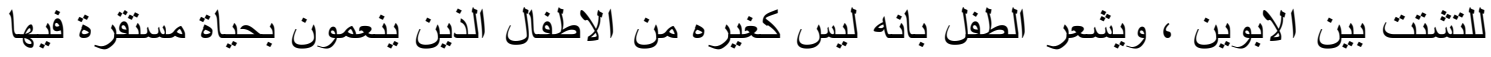

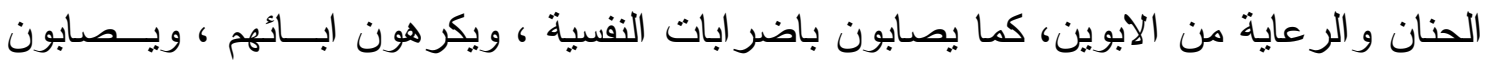




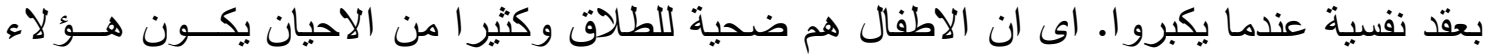

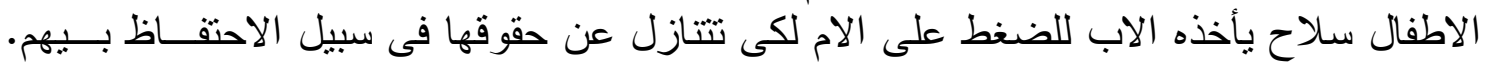

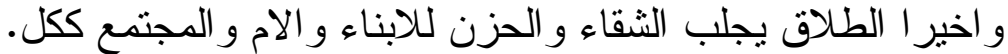

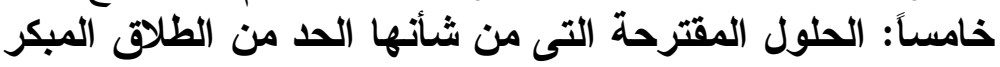

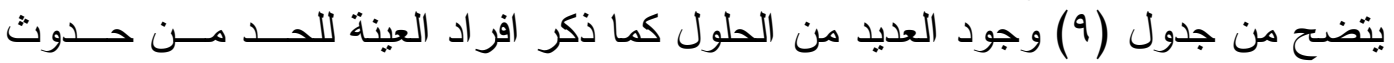

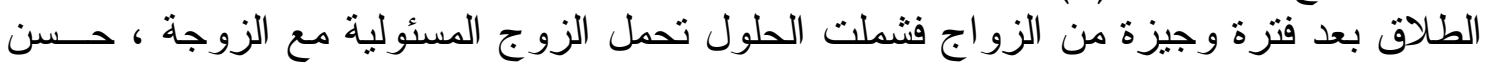

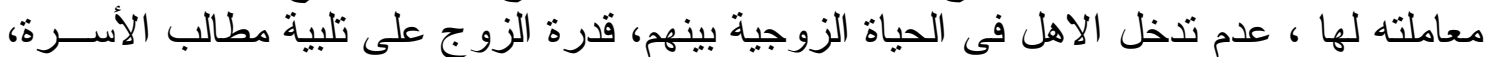

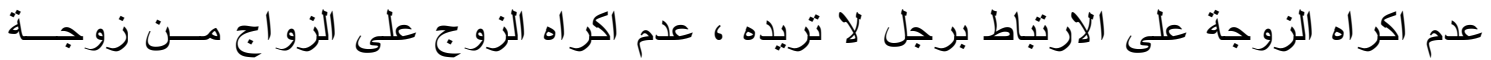

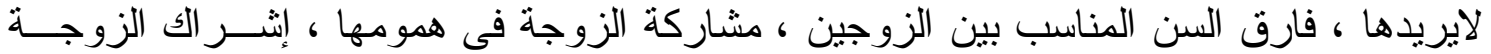

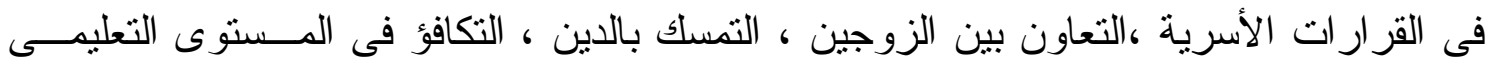

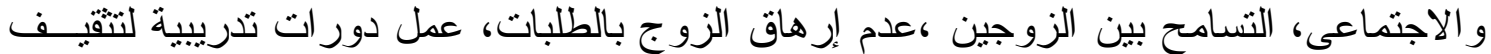

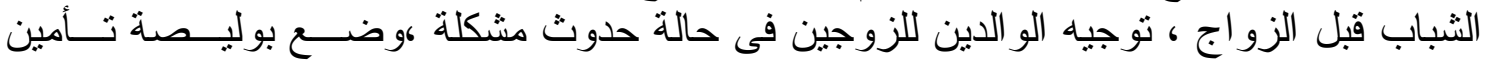

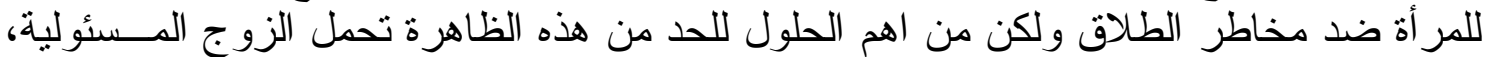

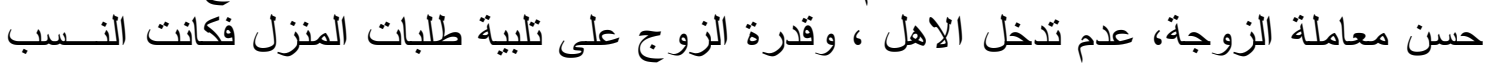

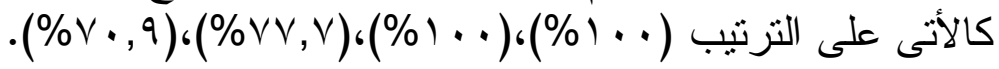

جدول 9 ـ التوزيع العددى والنسبى الحلول المقترحة التى من شأنها الحد من الطلاق

\begin{tabular}{|c|c|c|c|c|c|}
\hline \multicolumn{2}{|c|}{ عدم اختيار } & \multicolumn{2}{|c|}{ اختيار } & \multirow{2}{*}{ أسباب الطلاق } & \multirow{3}{*}{ p } \\
\hline$\%$ & 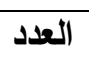 & $\%$ & 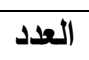 & & \\
\hline $1 \ldots$ & rVA & $1 \ldots$ & rVA & اجمالى عدد المبحوثات & \\
\hline- & - & $1 \cdots$ & rVA & تحمل الزوج المسئولية & 1 \\
\hline- & - & $1 \cdots$ & rVA & حسن معاملة الزوج لزوجته & $r$ \\
\hline TY,r & $\pi T$ & $V \vee, V$ & YIT & عدم تدخل الاهل & $r$ \\
\hline$r 9,1$ & $\wedge 1$ & $V \cdot, 9$ & $19 V$ & قدرة الزوج على تلبية مطالب الاسرة & $\varepsilon$ \\
\hline$r \cdot, \tau$ & 10 & $79, \varepsilon$ & 194 & عدم اكر اه الزوجة على ارتباط برجل لاتريده & 0 \\
\hline$r, r$ & $\Lambda V$ & $7 \curlywedge, \vee$ & 191 & عدم اكر اه الزوج على الزو اج بزوجة لايريدها & 7 \\
\hline$r, V$ & $\wedge \wedge$ & $7 \wedge, r$ & 19. & فارق السن مناسب & V \\
\hline$r r_{,} \cdot$ & $\wedge 9$ & $7 \wedge$, & 119 & مشاركة الزوجة فى همومها و احز انها & $\wedge$ \\
\hline$r r, \varepsilon$ & 9. & $7 V, T$ & 111 & اثر الك الزوجة فى القرار ات الاسرية & 9 \\
\hline rT,O & 94 & 77,0 & 110 & التعاون بين الزوجين & 1 . \\
\hline$r 0, r$ & 91 & $7 \varepsilon, V$ & $1 \wedge$ & التمسك بالدين & 11 \\
\hline$\varepsilon \cdot, \cdot$ & 111 & $7 \cdot, \cdot$ & $17 V$ & التكافؤ فى المستوى الاجتماعى & Tr \\
\hline$\varepsilon \cdot, V$ & $11 \%$ & $09, r$ & 170 & التكافؤ فى المستوى التعليمى & 14 \\
\hline$\varepsilon r, \varepsilon$ & 111 & $0 V, T$ & 17. & التسامح بين الزوجين & $1 \varepsilon$ \\
\hline$\varepsilon r, \Lambda$ & 119 & $O V, Y$ & 109 & عدم ارهاق الزوج بالطلبات & 10 \\
\hline$\sum 7, \varepsilon$ & 149 & or, 1 & $1 \leq 9$ & عمل دور ات تدريبية لتقيف الشباب قبل الزواج & 17 \\
\hline$\varepsilon \vee, \Lambda$ & ITH & or,, r & $1 \leq 0$ & على الو الدين توجيه الزوجين فى حالة حدوث مشكلة & IV \\
\hline$\varepsilon 9, V$ & $1 \mathrm{\mu N}$ & $0 \cdot, r$ & $1 \leqslant$ & وضع بوليصة تأمبن للمر أة ضد مخاطر الطلاق & 11 \\
\hline $1 \cdots$ & TVA & - & - & وجود مؤسسات تحاول حل المشاكل بين الزوجين & 19 \\
\hline
\end{tabular}




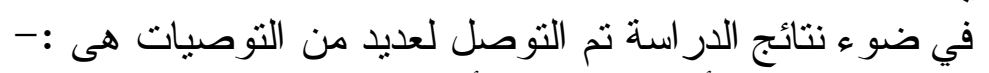

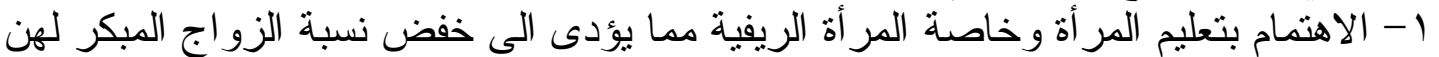

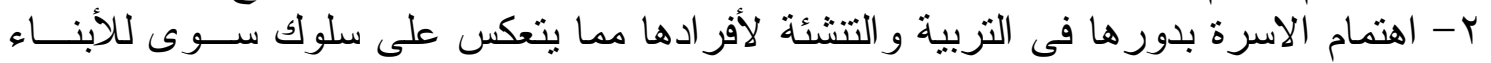

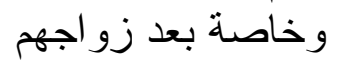

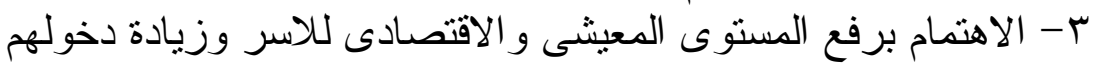

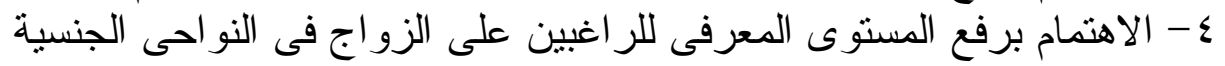

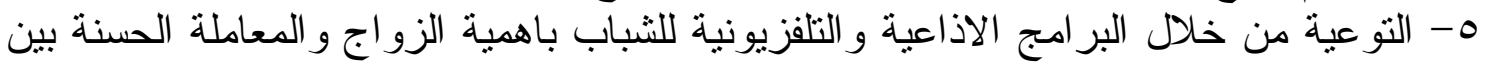
الطرفين

7- يجب على الطرفين الاختيار الجيد من البداية على اساس التكافؤ بين الطرفين

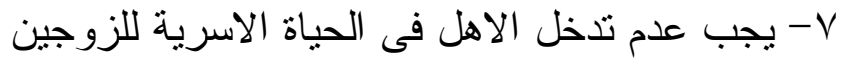

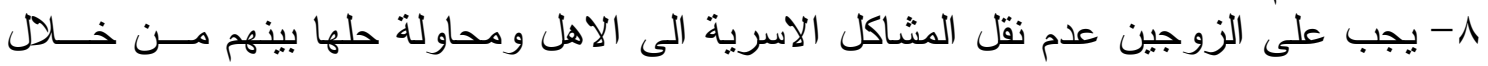
الحوار و المناقثنة

9- ادخال بر امج تعليمية عن الاسرة فى مناهج التعليم للطلاب من شأنها تهيئة الــشباب لحيــاة زوجية مستقرة

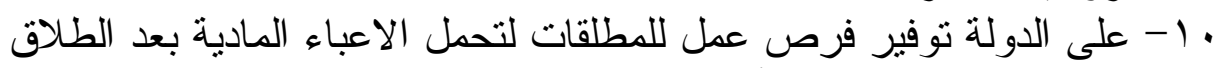

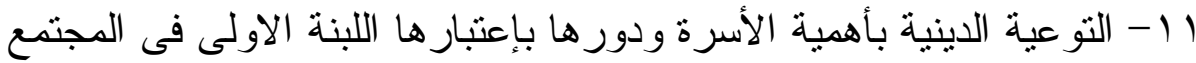

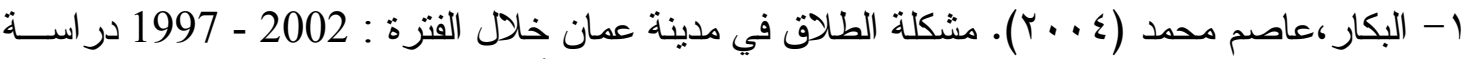
إجتماعية، رسالة ماجستير ،كلية الدر اسات العليا ، الجامعة الأردنية النانة

Website,htpp://www.0710genb1.1103.y.http.search.mandumah.com, Retrieved November 17,2016 10:03pm

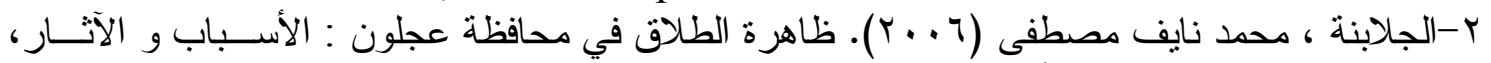
رسالة ماجستير، كلية الأداب ، جامعة البه البرموك

Website,http:/www./0710genb1.1103.y.http.search.mandumah.com.

Retrieved November 17.2016, 12:50Pm

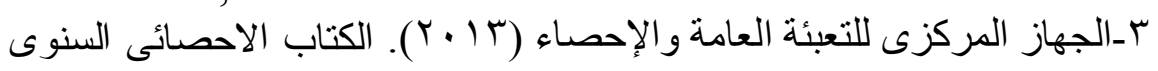

Website,http://www.capmas.gov.eg/pdf

Retrieved November 28.2016, 10:05pm

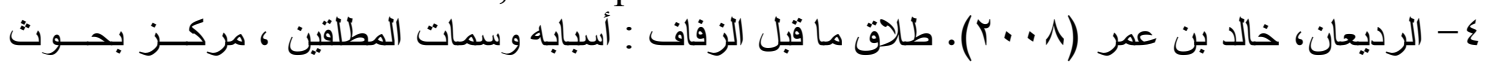

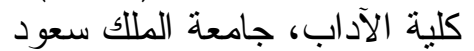

Website,htpp://www.repository.ksu.edu.sa/jspui/handle/123456789/16439?locale=ar

Retrieved August 4.2016, 6:40Pm

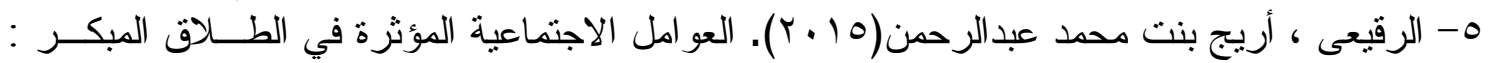

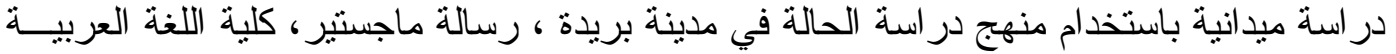
و الدر اسات الإجتماعية ، جامعة منجة القصيم

Website,http:/www/0710genb1.1103.y.http.search.mandumah.com.

Retrieved November 17.2016, 12:07Pm

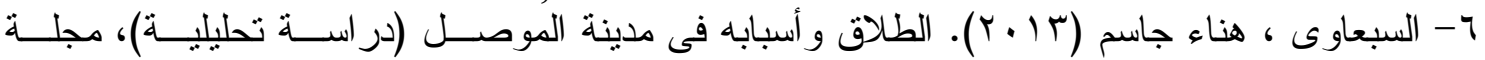

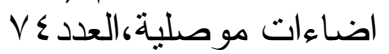

Website,http://www.mosulstudiescenter.uomosul.edu.iq/files/pages/page_6907433.pdf Retrieved August 4.2016, 5:35Pm 


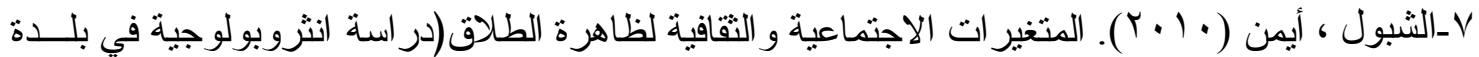

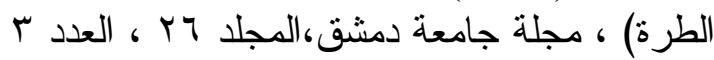

Website, htpp://www..damascusuniversity.edu.sy/mag/human/images/.../647-705.pdf Retrieved August 4.2016, 6:35Pm

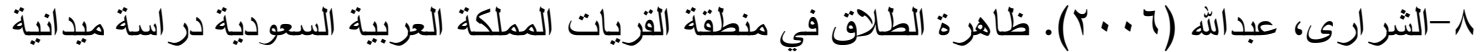

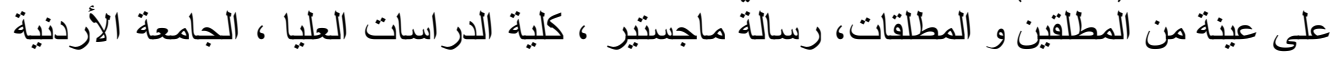

Website,htpp://www.http://0710genb1.1103.y.http.search.mandumah.coms Retrieved November 17.2016, 12:46Pm

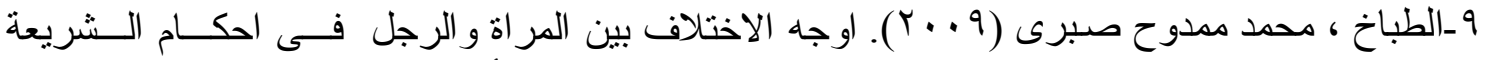

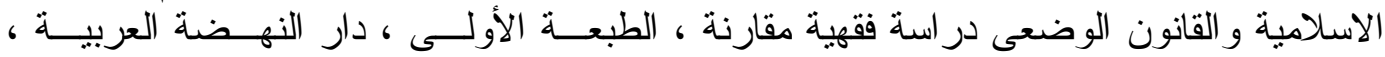

\section{القاهرة}

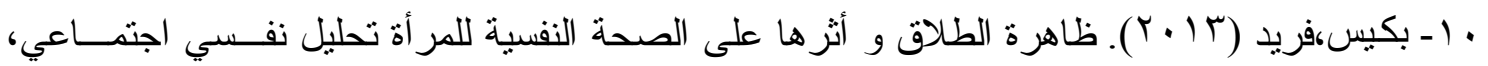

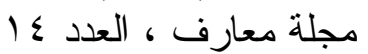

Website,htpp://ww.univ-bouira.dz/.../publications-nationales-fshs

Retrieved September 9 2016, 1:46Pm

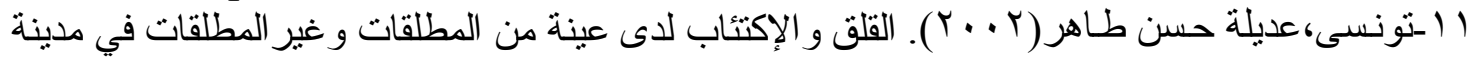

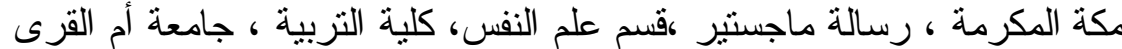

Website,htpp://www.elibrary.mediu.edu.my/books/2014/MEDIU17679.pdf Retrieved August 4 2016, 6:38Pm

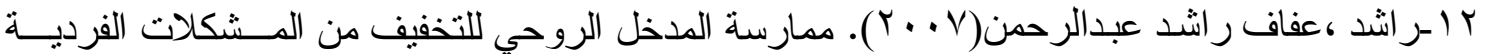

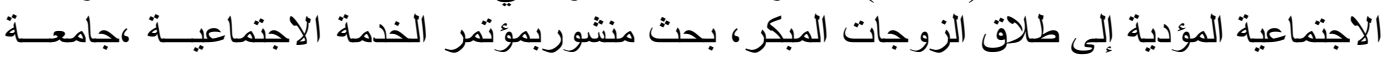

$$
\text { حلوان. }
$$

Website,http://0710genb1.1103.y.http.search.mandumah.com

Retrieved November 17 2016, 12:24Pm

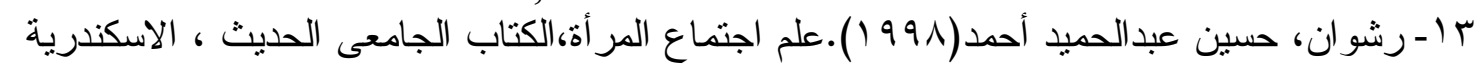

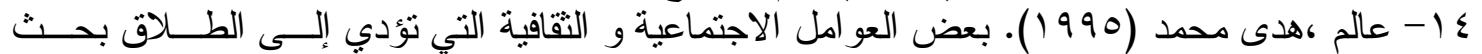

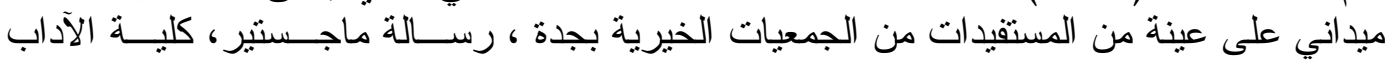

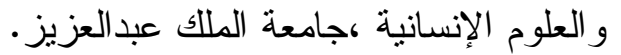

Website,http:/www./0710genb1.1103.y.http.search.mandumah.com.

Retrieved November 17 2016, 01:04Pm

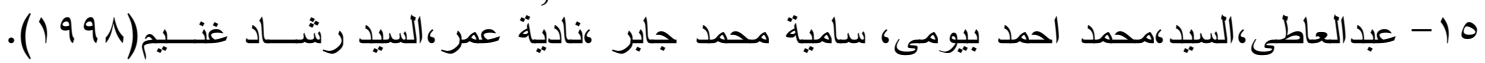
علم اجتماع الأسرة ، دار المعرفة الجامعية ، الاسكندرية.

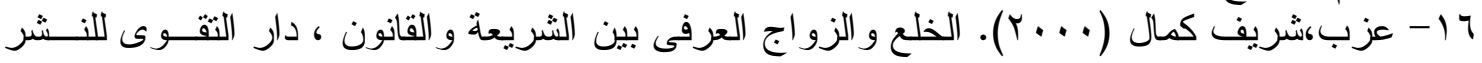

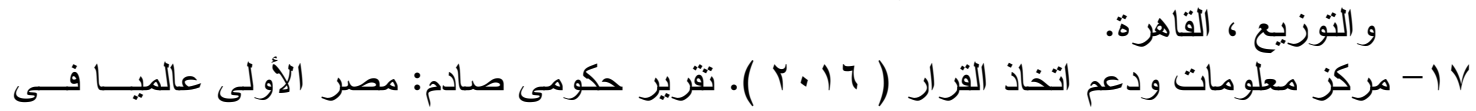
الطلاق

Website,http://www.idsc.gov.eg

Retrieved November,29.2016,01:30Pm

11 - موسى ،عبدالفتاح تركى (991 ()). البناء الاجتماعى للاسرة ، المكتب العلمى للنــشر والتوزيــع ،

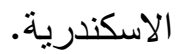

Website, htpp://www..wikipedia.com

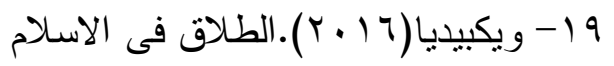

Retrieved December,25.2016,10:30Am 
1- Abebe, Yohannes Mekonnen (2015). Lived Experiences of Divorced Women in Rural Ethiopia. A Special Focus in Hulet Ejju Enessie Woreda: Addis Zemen Kebele, International Journal of Political Science and Development, Vol.3, No6 website, htpp://www.academicresearchjournals .org/IJPSD/../ Abebe.pdf, Retrieved Junary, 3.2016,9:26Am.

2- D’Onofrio, Brian M.(2011). Consequences of Separation/Divorce for Children website,htpp:/www.child-encyclopedia.com/divorce...separation/.../ co. Retrieved Junary,3.2016,01:22Am.

3- Fagan, Patrick F. (2012). The Effects of Divorce on Children Website,htpp://www.downloads.frc.org/EF/EF12A22.pdf,Retrieved Junary, 3.2016,10:41Am.

4- Harkonen, Juho (2013). Divorce: Trends, Patterns, Causes, Consequences Website, htpp://www. researchgate.net, Retrieved Junary,3.2016,09:53Am.

5- Mohi, Grant W.(2015). Positive Outcomes of Divorce: A Multi-Method Study on the Effects of Parental Divorce on Children, The University of Central Florida Undergraduate Research Journal, Vol.7, N0.2 website, https://www.urj.ucf.edu/docs/mohi.pdf Retrieved Junary,3.2016, 10:53 Am.

6-Olaniyi, Adeniran Adetayo (2015). Analytical Study of the Causal Factors of Divorce in African Homes, Research on Humanities and Social Sciences, Vol.5, No.14 website, htpp://www.iiste.org/Journals/index.php/RHSS /article/.../25115 Retrieved Junary,3.2016,9:15Am.

7-Sharma, Bharti (2011). Mental and Emotional Impact of Divorce on Women, Journal of The Indian Academy of Applied Psychology, Vol.37, No.1 Website, htpp://www.jiaap.org/.../5fd3f8b2-9fb6-4934-9c1f-0ab50f31 ea09. pdf. Retrieved Junary,3.2016,9:23Am. 


\title{
Study the Phenomenon of Early Divorce in Rural Assiut Governorate
}

\section{Randa Youssef Mohammed}

Department of the Rural Community and Agricultural Extension Faculty of Agriculture - Assiut University

\begin{abstract}
God has been praised humans over all other creatures by creating a partner to him whom he could find comfort. God makes love and mercy between them all the time through this holy thick bound, which is represented at marriage. But because of the economical, social, technological changes which are getting bigger year after year that affects negatively on the family relations which causes the splitting up between the couples and causes the divorce, and lately the early divorce becomes a phenomena that causes a great concern. The early divorce is the divorce which happens at the first five years of the marriage, It has been spread widely at the society. From this point the reason we choose this problem to study. We have studied this problem at rural area of Assiut the country side of Assiut, we identify the reasons and the effects of the divorce on women and children also the ways to stop this problem. So we identify the cities which have the highest number of divorce cases through the first five years of marriage which has been introduced to the family court at Assiut, these cases has been adjudicated divorce. The cities are Assiut, Dairout, Aboutiej, Fateh, then we have chosen the cities which have the largest number of these cases at all and they are Mankabad, Dairout el shrief, Balayza, and Wasta.

Then we identify the names of the ladies who belong to these cases at the family court in 2015. The number of these ladies was 1100 and the sample has been taken randomly of 278 divorced lady.

The data has been gathered by interviewing ach one of these ladies by using a questionnaire which has been used for this specific purpose. The results was most of these divorced ladies have educational degrees less the university degree, most of these ladies have been married at young ages, most of these ladies live with their husbands' families. About the reasons of the divorce there are many reasons lead to the divorce, some of these reasons are psychological, economical, physical. About the effects of the divorce to the women, there are many effects. One of the most important effects of the divorce on women was the financial obstacles, which the women would face alone because of the financial commitment, and the troubles the women would face because of the people's harassment. About the effects of the divorce on children, usually the children has been distracted between the two divorced parents. Also when they are older they would have psychological problems and they usually hate their father. About the solutions we suggest that the most important solution is taking the husband the whole responsibility of the family, also the gentle treating to the wife, also the separation between the husbands' parents and the couples, and finally the ability of the husbands to meet the family demands.
\end{abstract}

